\title{
Concise, stereodivergent and highly stereoselective synthesis of cis- and trans-2-substituted 3-hydroxy- piperidines - development of a phosphite-driven cyclodehydration
}

\author{
Peter H. Huy ${ }^{* 1, \S}$, Julia C. Westphal ${ }^{2}$ and Ari M. P. Koskinen ${ }^{* 1}$
}

\section{Full Research Paper}

Address:

${ }^{1}$ Aalto University, School of Chemical Technology, Laboratory of Organic Chemistry, Kemistintie 1, 02015 Espoo, Finland and

${ }^{2}$ University of Cologne, Department of Chemistry, Organic Chemistry,

Greinstrasse 4, 50939 Cologne, Germany

Email:

Peter H. Huy* - peter.huy@uni-saarland.de; Ari M. P. Koskinen* ari.koskinen@aalto.fi

* Corresponding author

$\S$ Current Address: Saarland University, Institute of Organic Chemistry, Mailbox 151150, 66041 Saarbrücken, Germany

Keywords:

amino acids; asymmetric synthesis; cyclodehydration;

hydroxypiperidines; natural products; one-pot

\begin{abstract}
Beilstein J. Org. Chem. 2014, 10, 369-383.
doi:10.3762/bjoc. 10.35
\end{abstract}

Received: 18 November 2013

Accepted: 16 January 2014

Published: 11 February 2014

This article is part of the Thematic Series "Natural products in synthesis and biosynthesis".

Guest Editor: J. S. Dickschat

(c) 2014 Huy et al; licensee Beilstein-Institut. License and terms: see end of document.

\begin{abstract}
A concise (5 to 6 steps), stereodivergent, highly diastereoselective (dr up to $>19: 1$ for both stereoisomers) and scalable synthesis (up to $14 \mathrm{~g}$ ) of cis- and trans-2-substituted 3-piperidinols, a core motif in numerous bioactive compounds, is presented. This sequence allowed an efficient synthesis of the NK-1 inhibitor L-733,060 in 8 steps. Additionally, a cyclodehydration-realizing simple triethylphosphite as a substitute for triphenylphosphine is developed. Here the stoichiometric oxidized P(V)-byproduct (triethylphosphate) is easily removed during the work up through saponification overcoming separation difficulties usually associated to triphenylphosphine oxide.
\end{abstract}

\section{Introduction}

1,2-Amino alcohols of the type A (Figure 1) represent a frequent core motif of many pharmacologically active natural products [1-9], chiral auxiliaries $[10,11]$ and catalysts for asymmetric synthesis [12-14]. Especially the 2-substituted 3-hydroxypiperidine scaffold of the general structure $\mathbf{B}$ (as one type of an 1,2-amino alcohol) can be found in numerous natural products and other bioactive compounds [1-7]. Selected examples are given in Figure 1: The non-peptidic human neurokinin1 (NK1) substance P receptor antagonists L-733,060 [15,16] and CP-99,994 [17-19], the natural product febrifugine (antimalarial) $[20,21]$ and antiprotozoal agent halofuginone (commercial trade names Halocur ${ }^{\circledR}$ (lactate salt) and Stenorol ${ }^{\circledR}$ (hydro- 


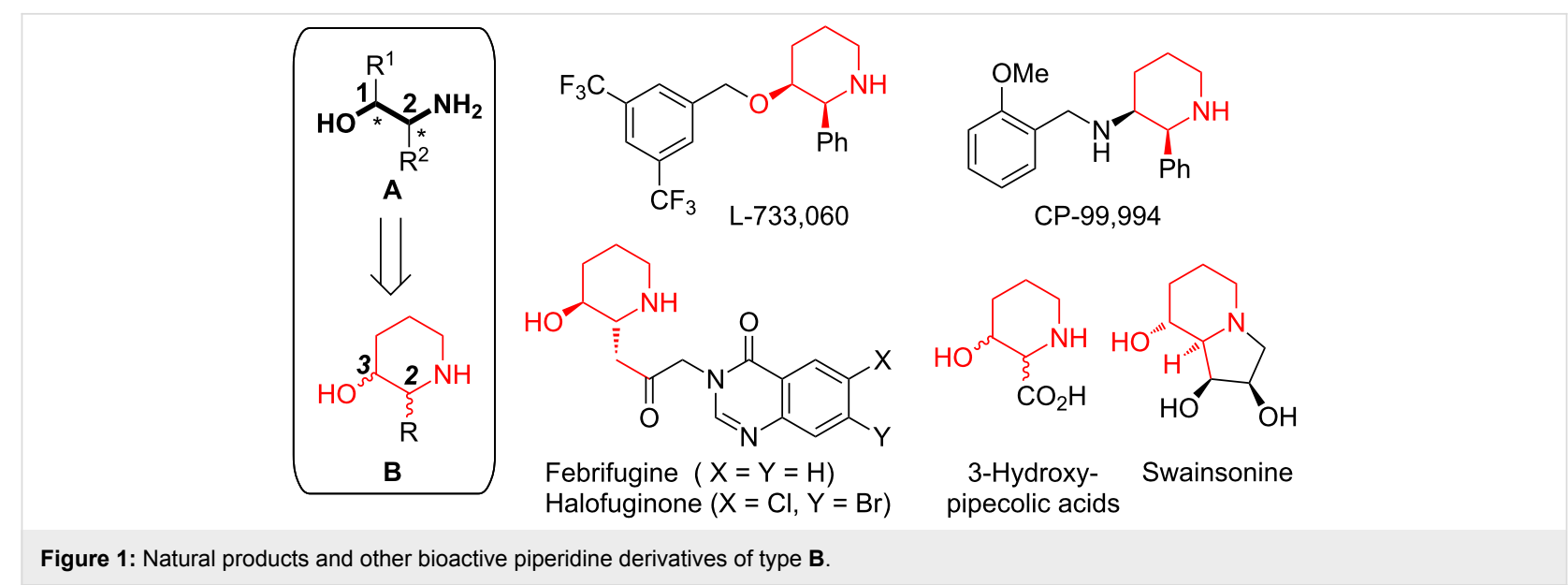

bromide salt)) [22]. Other relevant examples are 3-hydroxypipecolic acids, which serve as (conformationally restricted) substitutes of proline and serine $[23,24]$ and have been incorporated into diverse bioactive peptidomimetics $[25,26]$, and the iminosugar swainsonine, a new potential chemotherapeutic agent $[27,28]$. Recently, analogs of halofuginone were discovered as inhibitors of tRNA synthetases [29-31].

The majority of the reported syntheses [2-4,32-35] are elaborate (far more than 10 steps), specific on one of the targets depicted in Figure 1 and therefore on one relative configuration (either cis- or trans), and have not been proven to be scalable. In our opinion the following examples represent the most efficient synthesis of 3-piperidinols of type $\mathbf{B}$ in terms of stepeconomy ( $<10$ steps to establish the core motif $\mathbf{B})$ : 1 . Charette [36] prepared the less bioactive enantiomers of L-733,060 and CP-99,994 through nucleophilic additions to chiral pyridylium salts and subsequent hydrogenation. 2. Cossy and Pardo [37,38] synthesized L-733,060 (formal total synthesis) and two (epimeric) hydroxypipecolic acid through ring expansions of 2-( $\alpha$-hydroxyalkyl)pyrrolidines deduced to proline. 3. Based on the ring expansion of Cossy and Pardo [37], O'Brien [39] realized the synthesis of L-733,060 ( $80 \%$ ee). The 2-( $\alpha$-hydroxyalkyl)pyrrolidine precursor was prepared from a protected pyrrolidine through sparteine-mediated enantioselective lithiation and subsequent hydroxyalkylation. 4. Recently, Pansare [40] reported the synthesis of L-733,060, CP-99,994 and a hydroxypipecolic acid through asymmetric organocatalytic vinylogous aldol addition as the key step.

While the syntheses by Charette [38] and Pansare [40] are restricted to piperidinols $\mathbf{B}$ in cis-configuration ( $\mathrm{dr}>19: 1$ and $8: 1$, respectively), the sequences of Cossy and Pardo [35] and O'Brien [39] are stereodivergent. Nevertheless, the observed diastereomeric ratios are low (1:1 and 2.3:1 for trans-B, respectively) at least for one of the epimers. Considering the versa- tile pharmacological activities of compounds based on the 3-piperidinol scaffold, a step-economic, scalable and stereodivergent synthesis of both cis- and trans-diastereomers of $\mathbf{B}$ in good diastereoselectivities is highly desirable.

In the syntheses of potentially new drug candidates scalability is a significant factor to provide sufficient substance amounts for clinical tests $[41,42]$. Additionally, alternatives in reactions driven by the formation of phosphine oxides from phosphines (e.g. the Appel and Mitsunobu reaction) are highly desired to improve atom economy (reduced waste amounts) and to circumvent difficulties in the separation of these by-products as demonstrated by a number of reviews [43-45]. Numerous protocols have been developed to improve these issues, mostly based on polymer supported or otherwise modified (more complex) phosphines [43-45]. Surprisingly, in this context simple and inexpensive phosphites $\left(\mathrm{P}(\mathrm{OR})_{3}\right)$ have only been applied as phosphine substitutes in one single example: Beal [46] utilized tri-isopropylphosphite in a Mitsunobu condensation of a guanine-derived nucleoside analog with benzylic alcohols providing simplified byproduct separation through improved water solubility ( of $\left.\mathrm{O}=\mathrm{P}(\mathrm{OiPr})_{3}\right)$. In our case we were not able to remove stoichiometric amounts of $\mathrm{OP}(\mathrm{OEt})_{3}$ (which is more hydrophilic than $\left.\mathrm{OP}(\mathrm{OiPr})_{3}\right)$ through an aqueous work up (without saponification). Moreover, pentavalent $\mathrm{P}(\mathrm{OEt})_{5}$ prepared from $\mathrm{P}(\mathrm{OEt})_{3}$ with diethylperoxide and ethylbenzenesulfonate, respectively, in an additional step, was reported to effect cyclodehydration of diols to furans and pyrans $[47,48]$ (for recent examples for cyclodehydration protocols see $[49,50])$. Thereby, the volatile products were separated from $\mathrm{O}=\mathrm{P}(\mathrm{OEt})_{3}$ through distillation.

After our initial short communication [51] about the stepeconomic and stereodivergent synthesis of trans- and cis-2substituted 3-piperidinols $\mathbf{B}$, we want to report the development of this sequence in more detail with a focus on the phosphite- 


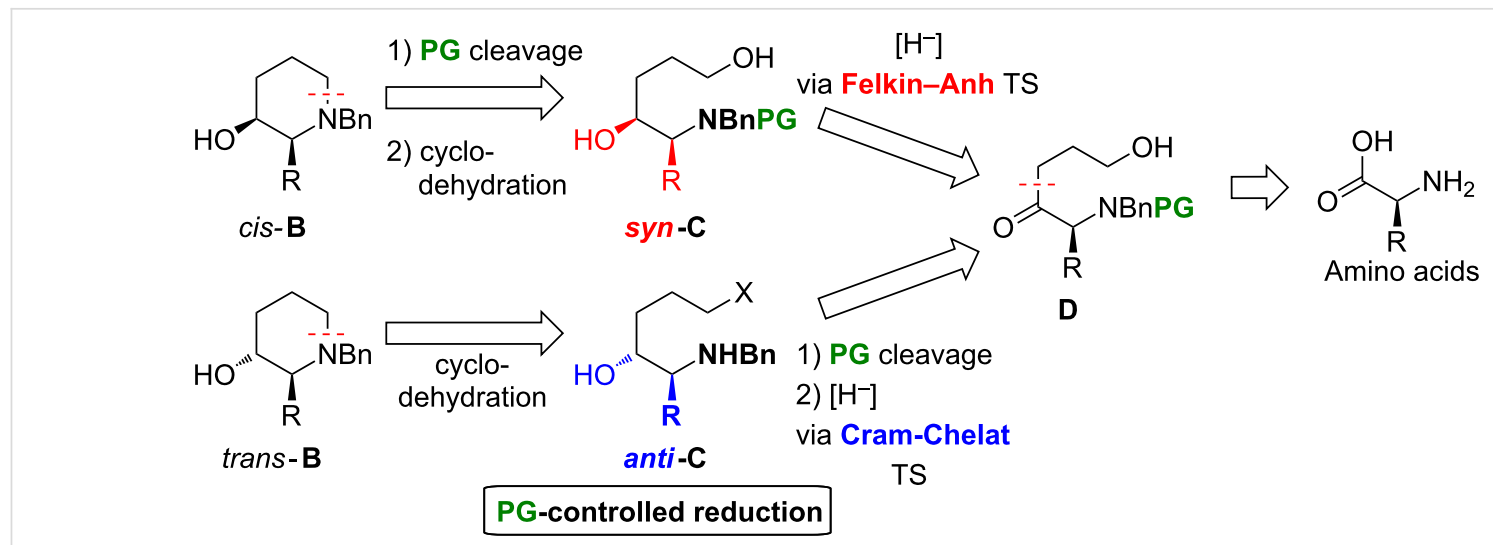

Figure 2: Retrosynthetic analysis of piperidines $B(X=O H$ or leaving group, $P G=$ protecting group).

mediated cyclodehydration. Additionally, the synthesis of a side chain functionalized piperidinol derived from methionine and studies towards the preparation of glutamic and aspartic acid derived heterocycles are presented.

Following the retrosynthetic analysis in Figure 2 the relative configuration of $\mathbf{B}$ (cis/trans) should be controlled through targeted protecting group (PG) manipulation: Reduction of the common precursor ketone $\mathbf{D}$ (derived from commercial available amino acids) should deliver the syn-amino alcohol $\mathbf{C}$ proceeding though a Felkin-Anh transition state [52,53] (due to the sterically demanding -NBnPG function). Further PG cleavage and cyclodehydration would give rise to $c i s-\mathbf{B}$. On the other hand, initial deprotection of $\mathbf{D}$ (to liberate the Lewis-basic -NHBn moiety) and subsequent reduction passing through a Cram-chelate transition state [54] should deliver the anti-amino alcohol C.

After subsequent cyclisation trans-B would result. Noteworthy, this strategy would completely circumvent configurationally labile amino aldehyde intermediates [55,56]. Basically any carbamate or amide protecting group (= PG) orthogonal to the benzyl moiety would be suitable for this strategy. Furthermore, we decided to surrender protection of the $\mathrm{OH}$ functions in the synthesis of intermediates $\mathbf{D}$ and $\mathbf{C}$ in order to minimize the number of steps of the sequence. Thus far only four examples following a related strategy to establish the syn- and anti-configuration of 1,2-aminoalcohol motifs have been reported [57$60]$.

\section{Results and Discussion Synthesis of hydroxyketone intermediates $D$}

In the first step L-alanine, phenylalanine, phenylglycine and methionine 1a-d were converted to their $N$-benzyl- $N$-carbamate-protected derivatives $\mathbf{2 a}-\mathbf{d}(\mathrm{PG}=\mathrm{Cbz}, \mathrm{Boc})$ in a practical one pot procedure through combination of Quitt's reductive benzylation protocol [61] and a Schotten-Baumann acylation $[62,63]$ in $70-95 \%$ yield (Scheme 1). While we choose a Cbz protecting group for the amino acids $\mathbf{1 a - c}$ due to the mild cleavage conditions (hydrogenolysis), we decided to introduce a

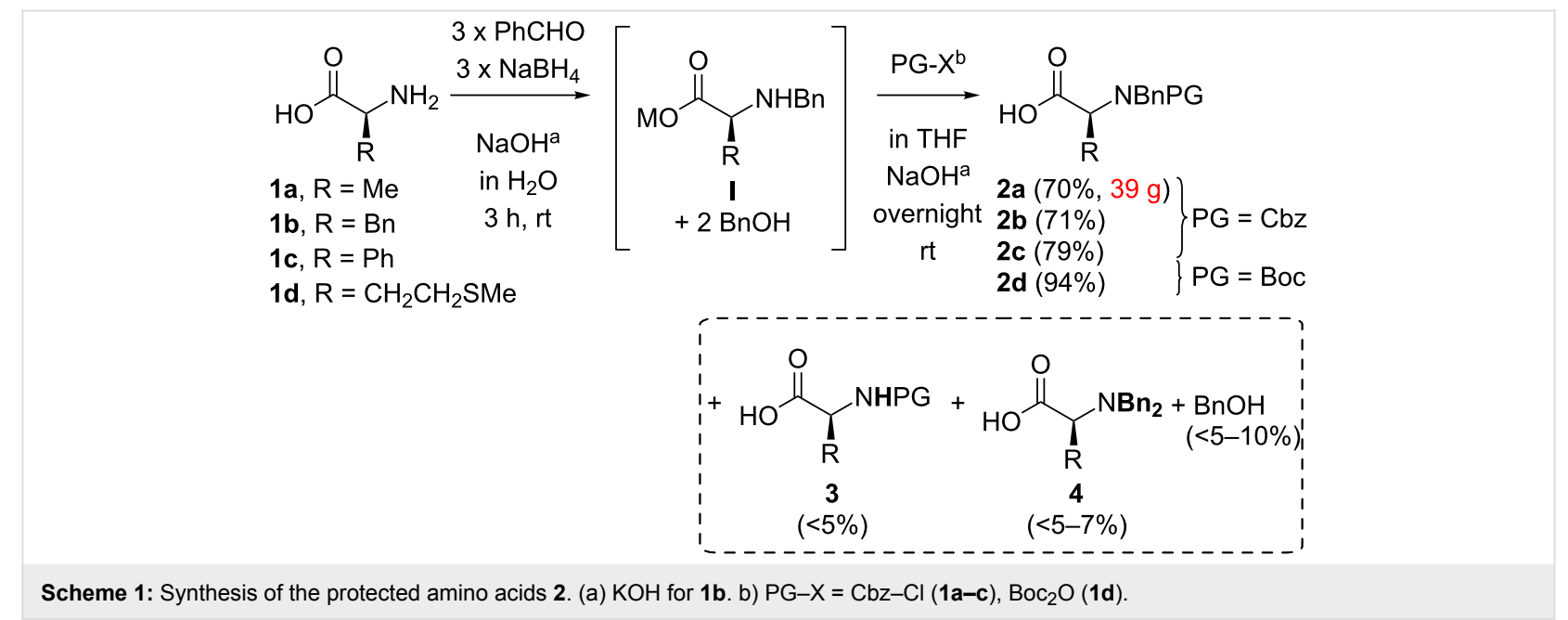


Boc group at the $N$-terminus of methionine 1d to avoid desulfuration $(-\mathrm{EtSMe} \rightarrow-\mathrm{Et})$ in the later deprotection.

In order to suppress the formation of the only carbamate protected amino acid derivatives $\mathbf{3}$ (remaining as impurity in the isolated products 2 ), quantitative benzylation $(\mathbf{1} \rightarrow \mathbf{I})$ was ensured by successive addition of three portions of benzaldehyde $/ \mathrm{NaBH}_{4}$ (Quitt's procedure [61] $\rightarrow$ two portions) and by maintaining the $\mathrm{pH}$ at a value of $10-11$. The extractive separation (washing of a basic aqueous solution of the acids 2 ) of the two equivalents of $\mathrm{BnOH}$ formed during the reductive amination $(\mathbf{1} \rightarrow \mathbf{I})$ proved to be challenging: Due to the high amphiphilicity of carboxylate salts of $\mathbf{2}$, mixtures in water and an organic solvent tend to form three distinct phases separating poorly. Nevertheless, washing of an aqueous solution of the polar lithium salts of $\mathbf{2}$ (crude $\mathbf{2}$ in aq. $\mathrm{LiOH}$ ) with organic solvents of increasing polarity $\left(\mathrm{Et}_{2} \mathrm{O} \rightarrow\right.$ EtOAc) allowed to remove $\mathrm{BnOH}$ almost completely $(<10 \%$ of $\mathrm{BnOH}$ referred to 2). Residual benzyl alcohol diminished the yield in the following amidation $(\mathbf{2} \rightarrow \mathbf{5})$ due to competitive formation of the corresponding benzyl esters. Depending on the $\mathrm{NaBH}_{4}$ batch the dibenzyl-protected derivatives $\mathbf{4}$ formed as side products $(<10 \%$ referred to 2$)$. The residual impurities $(\mathrm{BnOH}$ and 4$)$ were separated either through work up (of amide 5a) or chromatographic purification (of amides $\mathbf{5} \mathbf{b}-\mathbf{d}$ ) after the following amidation $(\mathbf{2} \rightarrow \mathbf{5})$.

Importantly, through this procedure not only one isolation step was avoided, but also the overall yield was improved significantly: For the transformation from 1a to $\mathbf{2 a}$ (I isolated as free acid) under (optimized) literature conditions we achieved a yield of $44 \%$ over two steps (59\% and $74 \%$, respectively) compared to $70 \%$ according to our direct conversion from 1a to $2 a$.

Next the carboxylic acids 2 were transformed to the Weinreb amides 5 with DCC and MeONHMe in 77-91\% yield (Scheme 2). While no racemisation occurred with substrates $\mathbf{2 a}$, 2b and 2d $\left(\mathrm{Et}_{3} \mathrm{~N} / \mathrm{DMAP}\right.$ or NMM as bases; Table 1, entries 1 and 2), the protected phenylglycine derivative $2 \mathrm{c}$ showed high configurational lability: Under standard conditions $\left(\mathrm{DCC}^{\mathrm{E}} / \mathrm{Et}_{3} \mathrm{~N} /\right.$ 0.3 equiv DMAP) the amide $\mathbf{5} \mathbf{c}$ was obtained in a diminished ee

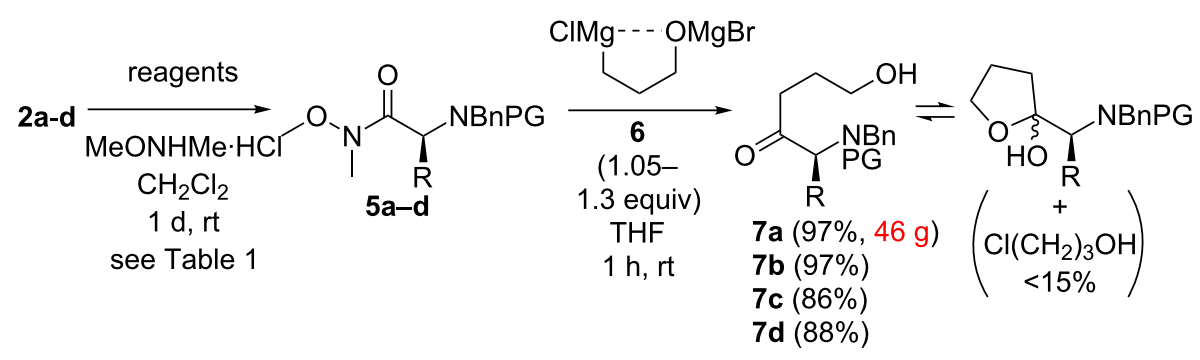

Scheme 2: Synthesis of hydroxy ketones $7(\mathrm{R}=\mathrm{Me}(\mathbf{a}), \mathrm{Bn}(\mathbf{b}), \mathrm{Ph}(\mathbf{c})$ and EtSMe (d); PG = Cbz (a-c), Boc (d)).

\begin{tabular}{|c|c|c|c|c|c|}
\hline entry & substrate & $\mathrm{R}$ & reagents & $e e^{a}$ & yield \\
\hline 1 & $2 a$ & $-\mathrm{Me}$ & DCC, NMM & $99 \%$ & $91 \% \mathrm{~b}$ \\
\hline 2 & $2 b$ & $-\mathrm{Bn}$ & $\mathrm{DCC}, \mathrm{Et}_{3} \mathrm{~N}, \mathrm{DMAP}$ (cat.) $^{\mathrm{d}}$ & $99 \%$ & $77 \% c$ \\
\hline 3 & & & $\mathrm{DCC}, \mathrm{Et}_{3} \mathrm{~N}, \mathrm{DMAP}$ (cat.) ${ }^{\mathrm{d}}$ & $49 \%$ & n.d. \\
\hline 4 & & & $\mathrm{DCC}, \mathrm{Et}_{3} \mathrm{~N}, \mathrm{HOBt}(\text { cat. })^{\mathrm{d}}$ & $5 \%$ & n.d. \\
\hline 5 & $2 c$ & $-\mathrm{Ph}$ & DCC, NMM, DMAP (cat.) ${ }^{\mathrm{d}}$ & $75 \%$ & n.d. \\
\hline 6 & & & DCC, NMM & $95 \%$ & $81 \%$ b \\
\hline 7 & & & T3P, pyridine $e^{\mathrm{e}}$ & $74 \%$ & n.d. \\
\hline 8 & $2 d$ & -EtSMe & DCC, NMM & $99 \%{ }^{f}$ & $91 \%$ b \\
\hline
\end{tabular}

aThe ee was determined via HPLC on a chiral stationary phase. ${ }^{\mathrm{b}}$ Isolated crude yield, purity $>90 \%$ according ${ }^{1} \mathrm{H}$ NMR. ${ }^{\mathrm{C}}$ Isolated yield after chromatography. ${ }^{d}$ cat. $=0.3$ equiv. e Solvent EtOAc instead of $\mathrm{CH}_{2} \mathrm{Cl}_{2}$. ${ }^{\mathrm{f}}$ The ee was determined to be $\geq 99 \%$ at the later stage the piperidinol cis-11d. DCC $=$ $N, N^{\prime}$-dicyclohexylcarbodiimide; NMM = N-methylmorpholine; DMAP = N,N-dimethylaminopyridine, $\mathrm{HOBt}=1$-hydroxybenzotriazole; T3P = $n$-propyIphosphonic acid anhydride; n.d. = not determined. 
of $49 \%$ (Table 1, entry 3 ). HOBt as nucleophilic catalyst proved to be even worse than DMAP, because under otherwise identical conditions the product $\mathbf{5 c}$ was isolated almost as a racemate (5\% ee, entry 4). By replacing $\mathrm{Et}_{3} \mathrm{~N}$ with the less basic NMM (in the presence of DMAP) the ee increased clearly $(49 \rightarrow 75 \%$, entry 5 ). However, without any nucleophilic catalyst the desired amide $\mathbf{5 c}$ was isolated with a very good ee of $95 \%$ (entry 6) [64].

The high racemisation sensitivity of $\mathbf{2 c}$ is further underlined by a T3P/pyridine (n-propylphosphonic acid anhydride) $[65,66]$ mediated amidation, which has been reported to suppress racemisation [67]. With substrate $\mathbf{2 c}$ the condensation product 5c was formed in a moderate ee of $74 \%$ (Table 1 , entry 7 ). The configurational lability of the phenylglycine derivative was not surprising, as phenylglycine itself is 60 times more prone to racemisation than alanine [68]. The optical purity of amides 5a-c, hydroxyketone 7c and piperidins cis-11a-d and trans-11a (Table 2, Scheme 6 and 7) was determined with HPLC on a chiral stationary phase and comparison with racemic samples (alanine 1a and phenylglycine 1c derived substrates) or in analogy to the aforementioned amino acid derivatives (phenylalanine $\mathbf{1 b}$ and methionine $\mathbf{1 d}$ deduced substrates).

In the next step, addition of a slight excess of the 3-chloropropanol-derived Grignard reagent 6 (final concentration $0.25-0.3 \mathrm{~mol} / \mathrm{L}$ ), which was found to be superior in the final concentration to the reported $\mathrm{ClMg} n \mathrm{PrOMgCl}$ derivative (0.1-0.2 $\mathrm{mol} / \mathrm{L}$ in our hands) [69], to amides $\mathbf{5 a - d}$ resulted in ketones 7a-d in good to excellent yields (86-97\%, Scheme 2). In contrast to the reported procedure (2-3 h of reflux) [69], short reflux times to form $6(20-30 \mathrm{~min})$ were crucial to avoid decomposition of this dianionic reagent. Furthermore, a slight excess of MeMgBr in the deprotonation step of 3-chloropropanol was found to assist the Grignard formation. Notably, with this strategy we saved additional protection and deprotection steps of the free hydroxy group of 7 . Thereby, only the phenylglycine derivative $7 \mathbf{c}$ displayed a slight decrease of ee $(95 \rightarrow 92 \%)$, the other hydroxy ketones $7 \mathbf{a}, 7 \mathbf{b}$ and $7 \mathbf{d}$ did not show any racemisation at all, not even after a longer time of storage. For the latter three the enantiomeric excess was not determined on this step: Further conversion as depicted in Scheme 4 and Table 2 delivered piperidinols 11a, 11b and 11d in $\geq 99 \%$ ee. As no intermediate in the conversion of $\mathbf{7}$ to $\mathbf{1 1}$ was crystallized, the ketones $\mathbf{7 a}, \mathbf{7 b}$ and $\mathbf{7 d}$ must have been enantiopure.

Residual 3-chloropropanol ( $<15$ mol \% referred to 7), which was difficult to separate chromatographically, was removed after the next step either during the work up (diols 9) or chromatographically (on the sequence leading to 15a). Interestingly, the ketones $\mathbf{7 a - d}$ existed in an equilibrium with their cyclic hemiacetal tautomers as shown in Scheme 2. The predominant keto form possessed a clear singlet around 205-210 ppm for the quaternary carbonyl carbon and the furan form was indicated by two weak signals at $105-110 \mathrm{ppm}$ for the hemiacetal carbon (two diastereomers) in the ${ }^{13} \mathrm{C} \mathrm{NMR}$.

Additionally, a short 3 step route to the functionalized glutamic and aspartic acid derived Weinreb amides 5e and $\mathbf{5 f}$ was coined as outlined in Scheme 3: At the outset both amino acids (1e and 1f) were subjected to esterification of the sterically less hindered side chain carboxyl function with acetyl chloride in $\mathrm{MeOH}$ [70-72]. Neutralization of the reaction mixture with $\mathrm{K}_{2} \mathrm{CO}_{3}$ and reductive benzylation [73] in one-pot then delivered the benzyl amines $\mathbf{8 e}$ and $\mathbf{8 f}$. While glutamic acid showed

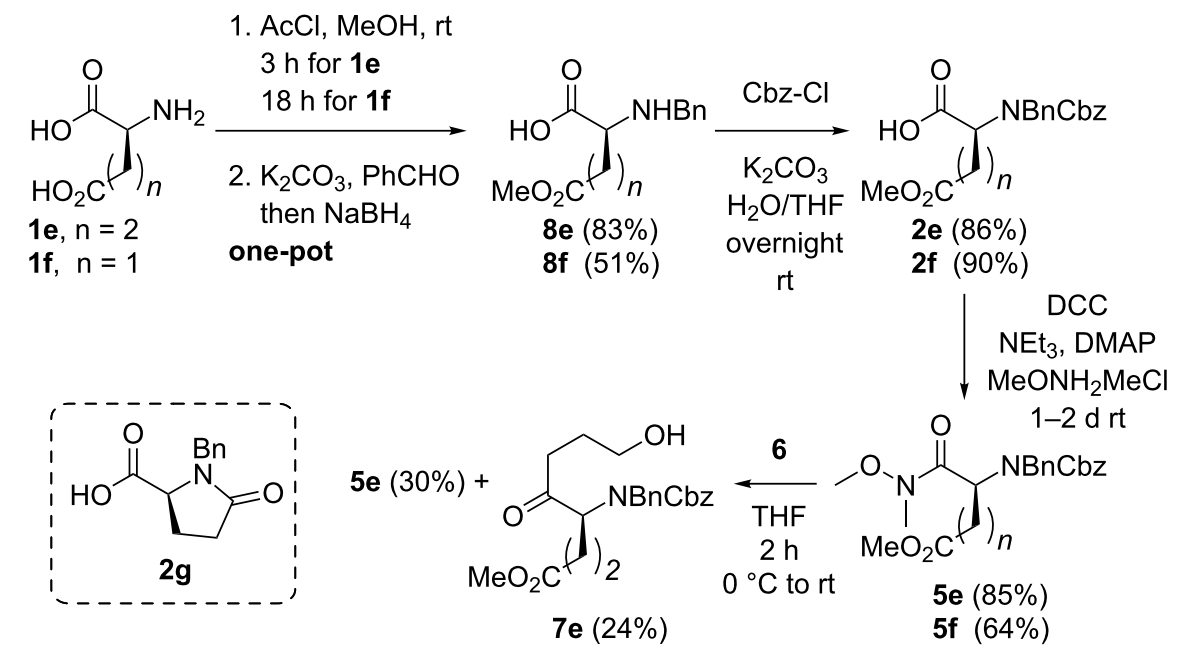

Scheme 3: Synthesis of amides $\mathbf{5 e}$ and $\mathbf{5 f}$ and ketone $\mathbf{7 e}$. 
selective mono esterification after $3 \mathrm{~h}$ at room temperature, the aspartic acid mono ester was obtained in a 5:1 ratio with the diester (not shown) after approximately $18 \mathrm{~h}$ of reaction time. Shorter reaction times in the esterification step of $\mathbf{1 f}$ decreased the yield of $\mathbf{8 f}$.

The amines $8 \mathbf{e}$ and $\mathbf{8 f}$ were converted in a straightforward manner to the carbamates $\mathbf{2 e}$ and $\mathbf{2 f}$ under Schotten-Baumann conditions $[62,63]$. Thus, $\mathrm{K}_{2} \mathrm{CO}_{3}(\rightarrow \mathrm{pH}=10)$ as the base prevented saponification of the side chain methyl ester functions (as observed with hydroxide salts). Nevertheless, in the acylation of the glutamic acid derivative 8e the corresponding pyroglutamic acid derivative $\mathbf{2} \mathbf{g}$ resulting from lactamisation of the ester function was observed as a side product in traces $(<5 \%)$. Next, amidation of the acids $2 \mathbf{e}$ and $\mathbf{2 f}$ gave the amides $\mathbf{5 e}$ and $\mathbf{5} \mathbf{f}$ in good yields under standard coupling conditions. Unfortunately, the ketone $7 \mathrm{e}$ was obtained in only $24 \%$ yield through addition of the Grignard reagent 6 to amide $5 \mathrm{e}$ (along with $30 \%$ of reisolated starting material), illustrating the tendency of reagent 6 to attack the side chain ester moiety.

\section{Synthesis of syn-amino alcohols $\mathrm{C}$}

Already the $\mathrm{NaBH}_{4}$ reduction (in $\mathrm{MeOH}$ at $-40 / 0{ }^{\circ} \mathrm{C}$ ) of ketones $7 \mathbf{a}$ and $7 \mathbf{b}$ and subsequent hydrogenolysis of the Cbzgroup in one-pot delivered the syn-amino alcohols $9 \mathbf{a}$ and $\mathbf{9 b}$ in good diastereomeric ratios (around 11:1 syn/anti, compare Scheme 4). In contrast the $\mathrm{NaBH}_{4}$ reduction of ketone $7 \mathbf{c}$ under identical conditions gave diol $9 \mathbf{c}$ without any selectivity $(\mathrm{dr}=$ 1.3:1). To our delight, reduction of the ketones $7 \mathbf{a}$ and $\mathbf{7 b}$ with L-Selectride [74] (or N-Selectride) and subsequent hydrogenolysis of the Cbz-group in one-pot delivered the benzyl amines syn-9a and $9 \mathrm{~b}$ in accordance with the Felkin-Anh model in excellent yields and as pure diastereomers as indicated by $400 \mathrm{MHz}{ }^{1} \mathrm{H}$ NMR (Scheme 4). Unfortunately, L-Selectride proved to be too unreactive at low temperatures towards the phenylglycine derived ketone $\mathbf{7 c}$, at higher temperatures mainly decomposition of the starting material was observed. Nevertheless, Superhydride $[75,76]$ reduction and successive Cbzcleavage gave the desired amino alcohol syn-9c in useful diastereomeric ratios of 3.7-4:1 syn/anti. The slightly diminished yield of $9 \mathbf{c}$ (74-77\%) compared to $9 \mathbf{a}$ and $9 \mathbf{b}(85-93 \%)$ is rationalized by formation of the oxazolidinone $10 \mathrm{c}$ as sideproduct. This cyclic carbamate results from the condensation of the alcoholate moiety of II with the Cbz-function passing the syn-periplanar conformation indicated in Scheme 4. With a bulky phenyl substituent $(=\mathrm{R})$ this conformation is higher populated than with smaller $\mathrm{R}$ groups (e.g. Me and $\mathrm{Bn}$ ) due to increased steric repulsion between the $n$-PrOH and R moiety. This explains the more facile formation of oxazolidinones of type 10 with the phenylglycine derived carbamate 7c. Indeed, if the excess of Selectride was quenched with acetaldehyde after reduction of $7 \mathbf{a}$, the oxazolidine $\mathbf{1 0 a}$ was obtained (under the basic reaction conditions) as the major product.

The outcome of the Cbz-cleavage strongly depended on the activity of the commercial $\mathrm{Pd} / \mathrm{C}$ batch: While an active catalyst led to a quantitative cleavage after $3 \mathrm{~h}$ (all substrates), less reactive batches led to considerably increased reaction times $(2 \mathrm{~d}$ for $7 \mathbf{a})$. For $7 \mathbf{b}$ and $7 \mathbf{c}$ the isolated yields of the amines 9 even dropped to $10-20 \%$ after 2 d reaction time due to incomplete $\mathrm{Cbz}$-cleavage. However, $\mathrm{Pd} / \mathrm{C}$ freshly prepared from $\mathrm{Pd}(\mathrm{OAc})_{2}$ and activated charcoal according to Felpin [77] delivered consistent results (reaction time $<3 \mathrm{~h}$ ). Although the Cbzcleavage beside a benzyl moiety in alcohols as solvent is known

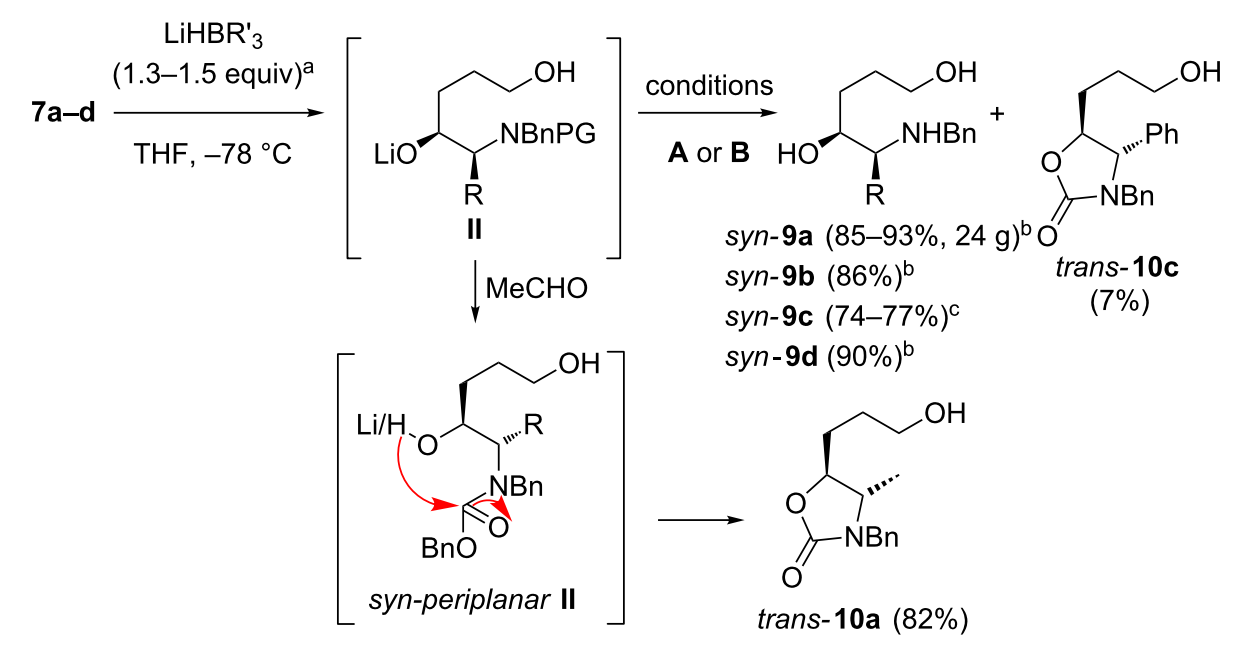

Scheme 4: Synthesis of amino alcohols syn-9a-d and oxazolidinone 10a. (for 7a-c conditions A: $\mathrm{H}_{2}(1 \mathrm{~atm}), \mathrm{Pd} / \mathrm{C}, \mathrm{HCl}, \mathrm{MeOH}(\mathrm{THF} / \mathrm{MeOH} 1: 1)$, rt, $3 \mathrm{~h}$; for $\mathbf{7 d}$ conditions $\mathbf{B}$ : $\mathrm{HCl}$ (aq.; $4 \mathrm{~N} \mathrm{HCl}$ in THF/ $\mathrm{H}_{2} \mathrm{O}$ ), rt, $6 \mathrm{~h}$ ) ${ }^{\text {a }} \mathrm{R}^{\prime}=\mathrm{sBu}$ for $\mathbf{7 a}, \mathbf{7 b}$ and $\mathbf{7 d}$ (L-Selectride); $\mathrm{R}^{\prime}=$ Et for $7 \mathbf{c}\left(\right.$ Superhydride). ${ }^{b} \mathrm{dr} \geq 19: 1$. ${ }^{c} \mathrm{dr}=3.7-4: 1$.) 
(for selected examples of the chemoselective Cbz-cleavage of Bn, Cbz-protected amines see [78-80]), we only achieved high chemoselectivities in the presence of an excess of $\mathrm{HCl}$.

In a similar manner the methionine derived Boc-protected ketone 7d was converted through L-Selectride reduction and Boc-cleavage induced by aqueous $\mathrm{HCl}$ solution in one pot to the syn-aminoalcohol 9d as a single diastereomer according to ${ }^{1} \mathrm{H}$ NMR. Importantly for up-scaling, only a slight excess of L-Selectride (1.3 equiv) or Superhydride (1.5 equiv), respectively, was required for the quantitative conversion of $\mathbf{7 a - d}$ to the intermediate II. Therefore the deprotonation of the free $\mathrm{OH}$-group of 7 must be significantly slower than the desired reduction of the carbonyl function. Practically, the residual 3 -chloropropanol remaining from the prior Grignard addition $\mathbf{5} \rightarrow \mathbf{7}$ step (vide supra) and $\mathrm{sec}-\mathrm{Bu}_{3} \mathrm{~B} / \mathrm{BEt}_{3}$ from the reduction were easily separated through washing with $\mathrm{Et}_{2} \mathrm{O}$ of an $(\mathrm{HCl})$ acidic, aqueous phase of the products 9 resulting in the crude diols $9 a-\mathbf{d}$ in a circa $90 \%$ purity according ${ }^{1} \mathrm{H}$ NMR. Hence, the crude amino alcohols 9 were not further purified before the following cyclodehydration.

\section{Synthesis of cis-piperidinols B}

Cyclodehydration of amino alcohol syn-9a to piperidinol cis11a under Appel conditions $\left(\mathrm{I}_{2}, \mathrm{PPh}_{3}\right)[81,82]$ surpassed by far Mitsunobu conditions and sulfonation (with $\mathrm{MsCl}$, TsCl) induced cyclisations (see Supporting Information File 1 for more details): Under optimized conditions (1.1 equiv $\mathrm{I}_{2}, \mathrm{Et}_{3} \mathrm{~N}$ in $\mathrm{MeCN}$ at $-40{ }^{\circ} \mathrm{C}$ ) the cyclic products $11 \mathrm{a}-\mathrm{c}$ were isolated in $68-77 \%$ yield and $90-99 \%$ ee (Table 2 entry 1, 10, 12). For work up the reaction mixture was simply absorbed on silica gel (ca. 9 fold amount of starting material 9) through evaporation of the solvent and directly subjected to chromatographic purification.

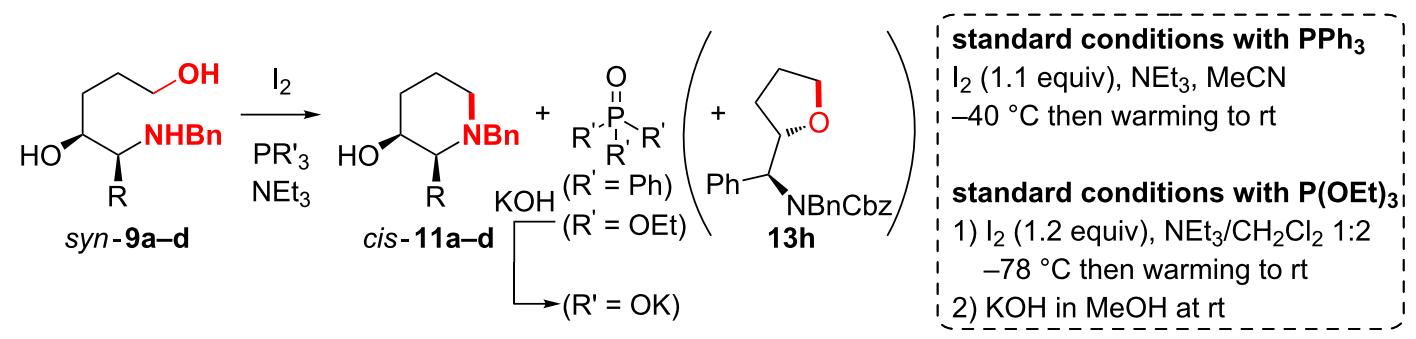

\begin{tabular}{|c|c|c|c|c|c|}
\hline entry & substrate & $\mathrm{R}$ & $\mathrm{PR}_{3}$ & deviation from standard conditions & yield \\
\hline 1 & \multirow{9}{*}{ syn-9a } & \multirow{9}{*}{$-\mathrm{Me}$} & $\mathrm{PPh}_{3}$ & - & $77 \%$ a,b,c \\
\hline 2 & & & $\mathrm{P}(\mathrm{OEt})_{3}$ & - & $82 \%$ a,b,c $(14 \mathrm{~g})$ \\
\hline 3 & & & $\mathrm{P}(\mathrm{OEt})_{3}$ & reflux instead of rt in saponification & $52 \% a, c$ \\
\hline 4 & & & $\mathrm{P}(\mathrm{OEt})_{3}$ & DIPEA instead of $\mathrm{Et}_{3} \mathrm{~N}^{\mathrm{e}}$ & $57 \%$ c,d \\
\hline 5 & & & $\mathrm{P}(\mathrm{OEt})_{3}$ & lutidine instead of $\mathrm{Et}_{3} \mathrm{~N}^{\mathrm{e}}$ & $50 \% c, d$ \\
\hline 6 & & & $\mathrm{P}(\mathrm{OEt})_{3}$ & imidazole instead of $\mathrm{Et}_{3} \mathrm{~N}^{\mathrm{e}}$ & $30 \% c, d$ \\
\hline 7 & & & $\mathrm{P}(\mathrm{OEt})_{3}$ & $\mathrm{Et}_{3} \mathrm{~N} / \mathrm{CH}_{2} \mathrm{Cl}_{2} 1: 10$ & $79 \% c, d$ \\
\hline 8 & & & $\mathrm{P}(\mathrm{OEt})_{3}$ & THF instead of $\mathrm{CH}_{2} \mathrm{Cl}_{2}{ }^{\mathrm{e}}$ & $58 \% \mathrm{c}, \mathrm{d}$ \\
\hline 9 & & & $\mathrm{P}(\mathrm{OEt})_{3}$ & $-20^{\circ} \mathrm{C}$ then warming to $0^{\circ} \mathrm{C}$ & $41 \% a, c$ \\
\hline 10 & \multirow{2}{*}{ syn-9b } & \multirow{2}{*}{$-\mathrm{Bn}$} & $\mathrm{PPh}_{3}$ & - & $68 \% a, b, c$ \\
\hline 11 & & & $\mathrm{P}(\mathrm{OEt})_{3}$ & - & $74 \% a, b, c$ \\
\hline 12 & \multirow{4}{*}{ syn-9c } & \multirow{4}{*}{$-\mathrm{Ph}$} & $\mathrm{PPh}_{3}$ & - & $77 \%{ }^{a, e, f}(2.3 \mathrm{~g})$ \\
\hline 13 & & & $\mathrm{P}(\mathrm{OEt})_{3}$ & $\mathrm{Et}_{3} \mathrm{~N} / \mathrm{CH}_{2} \mathrm{Cl}_{2} 1: 1.3$ & $68 \% a, e, f$ \\
\hline 14 & & & $\mathrm{P}(\mathrm{OEt})_{3}$ & - & $49 \%$ a,f \\
\hline 15 & & & $\mathrm{P}(\mathrm{OEt})_{3}$ & $\mathrm{Et}_{3} \mathrm{~N} / \mathrm{CH}_{2} \mathrm{Cl}_{2} 1: 3$ & $22 \% a, f$ \\
\hline 16 & syn-9d & -EtSMe & $\mathrm{P}(\mathrm{OEt})_{3}$ & - & $74 \%$ a,b,c \\
\hline
\end{tabular}

alsolated yield after chromatographic purification. ${ }^{b}$ ee $\geq 99 \%$, determined by HPLC on a chiral stationary phase. ${ }^{\mathrm{c}} \mathrm{dr}>19: 1$ cis/trans. ${ }^{\mathrm{d}}$ Yield determined with naphthalene as NMR-standard. ${ }^{e}$ Ratio base/solvent $1: 10 .{ }^{f} e e=90 \%$; dr = 4.0:1 (entry 12), 5.3:1 (entry 13), 3.7.1 (entry 14 ), $3.0: 1$ (entry 15) cis/trans. DIPEA = di-isopropylethylamine; lutidine $=2,6$-dimethylpyridine. All reactions were run until full conversion of the starting material 9. 
Unfortunately, the stoichiometric byproduct triphenyl phosphine oxide was only separable by chromatography requiring significantly increased amounts of silica gel (the crude product weight usually obtained $300-400 \%$ of the theoretical yield after aqueous work up). Attempts to crystallize $\mathrm{OPPh}_{3}$ beside the piperidine 11a or of the fumaric acid salt of 11a for instance failed, only an oily mixture of $\mathbf{1 1 a}$ and $\mathrm{OPPh}_{3}$ precipitated. Separation of $\mathrm{OPPh}_{3}$ through washing of an aqueous solution of hydrochlorides of $\mathbf{1 1}$ led to a significant loss of piperidines $\mathbf{1 1}$ (especially with $\mathbf{1 1 b}$ and $\mathbf{1 1 c}$ bearing lipophilic side chains R).

In general, the reaction of alcohols with alkyl phosphites $\left(\mathrm{P}(\mathrm{OR})_{3}\right)$, activated through oxidants such as iodine, have been reported to give the corresponding phosphates in a Michaelis-Arbuzow type reaction [83-85] (Scheme 5). In order to improve atom economy and side product separation, we rationalized that in the phosphonium intermediate III (originating from activation of the diol/amino alcohol E) the intramolecular substitution by the amino function (delivering the desired heterocycles of type $\mathbf{G}$ ) should be significantly faster than the bimolecular reaction of the iodide ion with intermediate III as indicated (resulting in the formation of the corresponding undesired phosphates F). The formation of heterocycles $\mathbf{G}$ passing phosphates $\mathbf{F}$ through substitution of the phosphate leaving group by the nucleophilic YH moiety would be in principal also a plausible explanation for the formation of F, but can most likely be excluded (see Supporting Information File 1).

Indeed, under optimized conditions (1.2 equiv $\mathrm{I}_{2}, \mathrm{P}(\mathrm{OEt})_{3}, \mathrm{Et}_{3} \mathrm{~N}$ (5-6 equiv) $/ \mathrm{CH}_{2} \mathrm{Cl}_{2} 1: 2 ;-78{ }^{\circ} \mathrm{C}$ then warming to $\mathrm{rt}$ ) the piperidinols 11a-d were isolated after saponification (during work up) of triethylphosphate and chromatographic purification in 68-82\% yield and high enantiomeric excess (90-99\%) (Table 2, entries 2, 11, 13 and 16).
For both cyclodehydration methods (with $\mathrm{PPh}_{3}$ and $\mathrm{P}(\mathrm{OEt})_{3}$ ) neat iodine was simply added to a solution of the amino alcohols $9 \mathbf{a}-\mathbf{d}$, the phosphorus reagent and $\mathrm{Et}_{3} \mathrm{~N}$ in the reaction solvent at the indicated temperature $\left(-40^{\circ} \mathrm{C}\right.$ and $-78^{\circ} \mathrm{C}$, respectively) and stirred at this temperature, until $\mathrm{I}_{2}$ had dissolved completely (1-2 h with $\mathrm{PPh}_{3}$ and $2-5 \mathrm{~h}$ with $\left.\mathrm{P}(\mathrm{OEt})_{3}\right)$. Then the usually heterogeneous mixture (through precipitated $\mathrm{Et}_{3} \mathrm{NH}^{+} \mathrm{Cl}^{-}$) was allowed to warm to room temperature to reach full conversion of the starting material 9. Due to the ammonium salt precipitation and the solid iodine for the large scale preparation of piperidinol 11a (14 g, Table 2, entry 2) mechanical stirring was preferred. For saponification, saturated $\mathrm{KOH}$ solution in $\mathrm{MeOH}$ (ca. $4 \mathrm{~N}$ ) was chosen, because aqueous $\mathrm{KOH}$ or $\mathrm{NaOH}$ solution would result in biphasic mixtures. A quantitative hydrolysis of the triethylphosphate side product required evaporation of $\mathrm{CH}_{2} \mathrm{Cl}_{2}$ and $\mathrm{Et}_{3} \mathrm{~N}$ (and $\mathrm{MeOH}$ ) after the addition of the methanolic $\mathrm{KOH}$-solution in vacuo, dilution with $\mathrm{MeOH}$, stirring at room temperature for ca. $1 \mathrm{~h}$, and a second concentration under reduced pressure. Most likely, the solubility of $\mathrm{KOH}$ in the $\mathrm{CH}_{2} \mathrm{Cl}_{2} / \mathrm{Et}_{3} \mathrm{~N} / \mathrm{MeOH}$ mixture is too low resulting in incomplete hydrolysis of the phosphate without evaporation of the solvent. Saponification at reflux on the other hand (in order to circumvent the solvent evaporations) led to partial decomposition of the product 11a (isolated yield 52\% after several hours of reflux, see Table 2, entry 3). Chromatographic purification of the crude piperidinols 11a-d, which were already isolated in $85-90 \%$ purity (from the phosphite cyclodehydration), was best achieved with halogen free iPrOH/ $\mathrm{Et}_{3} \mathrm{~N} /$ hexane eluent mixtures (ratio 0.8-3:2-4:100 depending on the polarity of the product). Although the diastereomers of piperidinol 11c (dr ca. 4:1 cis/trans) were chromatographically separable, we decided to separate them after protecting group exchange at the stage of the Boc carbamate 16c (see Scheme 8), because the epimers of the latter one were much easier to isolate.

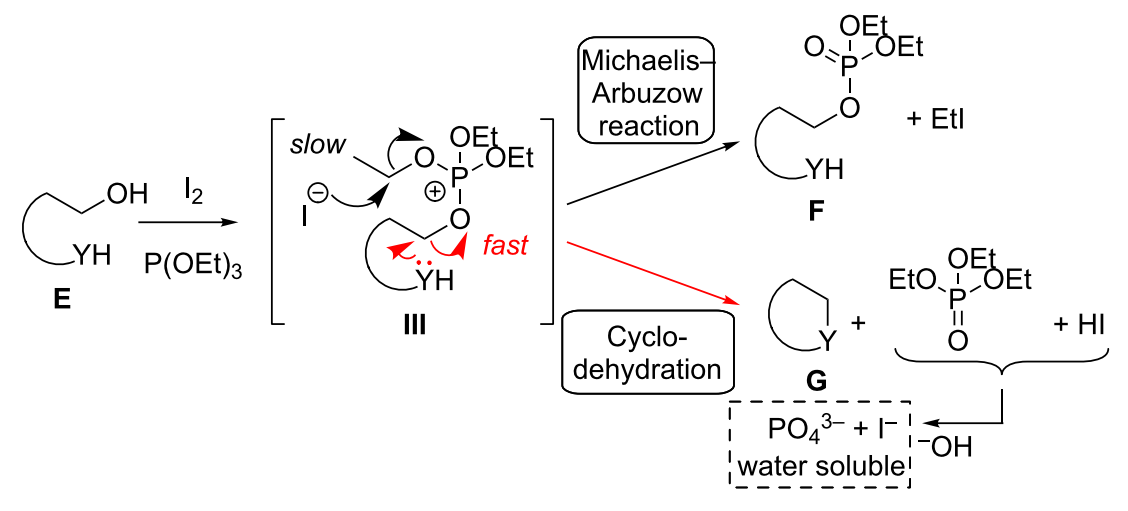


Interestingly, we observed a high specificity in the base: With pyridine, NMM, DMAP and DBU (1,8-diaza[5.4.0]bicycloundec-7-ene), respectively, (instead of $\mathrm{Et}_{3} \mathrm{~N}$ ) the desired heterocycle 11a was only formed in traces. DIPEA, lutidine and imidazole delivered 11a in clearly diminished yields of 30-57\% (Table 2, entries 4-6) compared to $\mathrm{Et}_{3} \mathrm{~N}$ (79\%, entry 7). For comparison we ran the condensation of amino alcohol 9a to piperidinol 11a in the same concentration as in Table 2, entries 4-6 and 8 (as opposed to the standard conditions) and determined the yield also through NMR-standard: The yield assigned in that way ( $79 \%$, entry 7 ) shows a decent match to the $82 \%$ isolated yield obtained under standard conditions (entry 2). Hence, the comparability of Table 2 entry 2 to entries $4-8$ is established. In conclusion NMM, pyridine and imidazole might be too weak bases, DBU might be too strong and a base favoring other reaction pathways then the desired cyclodehydration. DIPEA and lutidine could be sterically too hindered and DMAP too nucleophilic inducing side reactions.

Moreover, we observed a strong influence of the ratio of $\mathrm{Et}_{3} \mathrm{~N} /$ $\mathrm{CH}_{2} \mathrm{Cl}_{2}$ with substrate $9 \mathrm{c}$ : The phenylglycine-derived hydroxypiperidine 11c was obtained in $68 \%$ yield in $\mathrm{Et}_{3} \mathrm{~N} / \mathrm{CH}_{2} \mathrm{Cl}_{2}$ in a $1: 1.3$ ratio, while a $1: 3$ solvent mixture gave $11 \mathrm{c}$ in only $22 \%$ yield (Table 2, entries 13-15). Indeed, the furan 13h (see Table 2) resulting from nucleophilic substitution of the primary (activated) $\mathrm{OH}$-function through the secondary hydroxy group of $9 \mathbf{c}$ formed in significant amounts in the cyclisation of amino diol 9c. This is explained by steric shielding of the amino function ( $\rightarrow$ decreased nucleophilicity) through the bulky phenyl group in $\alpha$-position (compared to the less demanding Me and $\mathrm{Bn}$ side chains $\mathrm{R}$ of substrates $9 \mathrm{a}$ and $\mathbf{9 c}$ ). As the R-substituent is in the $\beta$-position of the secondary $\mathrm{OH}$-function of diols $\mathbf{9}$, this hydroxy moiety is less shielded. For substrate $\mathbf{9 c}$ the yield could not be improved further, because in higher ratios $\mathrm{Et}_{3} \mathrm{~N} / \mathrm{CH}_{2} \mathrm{Cl}_{2}$ iodine did not completely dissolve (react) at $-78^{\circ} \mathrm{C}$ in a reasonable time $(<12 \mathrm{~h})$.

This strong influence of the ratio of $\mathrm{Et}_{3} \mathrm{~N} / \mathrm{CH}_{2} \mathrm{Cl}_{2}$ can be attributed to the lower solubility of iodine in $\mathrm{Et}_{3} \mathrm{~N}$ (which leads to a slower and thus more selective reaction) and general base catalysis: Simultaneous deprotonation (through $\mathrm{Et}_{3} \mathrm{~N}$ ) in the cyclisation step strongly favours the desired reaction pathway to piperidines 11. Due to this effect we chose a ratio of $\mathrm{Et}_{3} \mathrm{~N} /$ $\mathrm{CH}_{2} \mathrm{Cl}_{2}$ 1:2 as standard conditions for the phosphite mediated cyclodehydration. Typically, 5 to 6 equivalents of $\mathrm{Et}_{3} \mathrm{~N}$ resulting in a reasonable concentration of the substrates $\mathbf{1 1}$ and 12 (see Table 3) of $0.4-0.5 \mathrm{~mol} / \mathrm{L}$ (in $\mathrm{Et}_{3} \mathrm{~N} / \mathrm{CH}_{2} \mathrm{Cl}_{2}$ ) were sufficient enough to guarantee magnetically stirring, as the viscosity of the reaction mixture increases through ammonium salt precipitation during the preceding reaction. Noteworthy, $\mathrm{Et}_{3} \mathrm{~N}$ is as cheap as common solvents such as THF and $\mathrm{CH}_{2} \mathrm{Cl}_{2}$.
Furthermore, in THF the yield of 11 a decreased to $58 \%$ (Table 2, entry 8), whereas in $\mathrm{MeCN}$ low conversions were observed most likely through reaction of the solvent with the $\mathrm{I}-\mathrm{P}(\mathrm{OEt})_{3}{ }^{+}$intermediate and in $\mathrm{Et}_{3} \mathrm{~N}$ as the sole solvent the solubility of iodine is too low. Even at room temperature iodine did not dissolve (= react) completely. Also a larger excess of iodine ( $>1.2$ equiv) has a negative effect on the yield, because the secondary hydroxy function probably is activated as well. With the more atom economic $\mathrm{P}(\mathrm{OMe})_{3}$ complex product mixtures were obtained (in the case of substrate 9a). Most likely the differentiation between the Michaelis-Arbuzow and cyclodehydration pathway (see Scheme 5) is declined. Moreover, the reaction temperature has a strong influence: When the condensation of $9 \mathbf{a}$ had been performed at $-20{ }^{\circ} \mathrm{C}$ for instance, piperidine 11a was isolated in only $41 \%$ yield (Table 2, entry 9). Interestingly, the activation of the primary $\mathrm{OH}$ function of substrates 9 in the presence of the secondary $\mathrm{OH}$ group proceeded (with $\mathrm{PPh}_{3}$ and $\mathrm{P}(\mathrm{OEt})_{3}$ ) in very high chemoselectivity most likely due to steric effects. The corresponding aziridine of 9a clearly resulting from activation of the secondary hydroxy group and subsequent fast 3-exo-trig cyclisation was only obtained as a sideproduct at higher temperatures $\left(\mathrm{I}_{2}, \mathrm{PPh}_{3}\right.$, imidazole, $\mathrm{CH}_{2} \mathrm{Cl}_{2}$ at $0{ }^{\circ} \mathrm{C}$; see Supporting Information File 1 for more details).

Significantly, $14 \mathrm{~g}$ of alanine derivative cis-11a were obtained (cyclodehydration with $\mathrm{P}(\mathrm{OEt})_{3}$ ) in one batch with no purification of the intermediates (2a, 5a, 7a and syn-9a) at all and an overall yield of $44 \%$, demonstrating the scalability and high practicability of our sequence. The relative configurations of compounds 9 and $\mathbf{1 1}$ were proven by NOE spectroscopy of piperidinols cis-11a-d, trans-11a, cis- and trans-16c, L-733,060 $\cdot \mathrm{HCl}$ and of oxazolidinones trans-10a and trans-10c (see Supporting Information File 1 for more details).

\section{Synthesis of other heterocycles through phosphite-mediated cyclodehydration}

We next wanted to demonstrate the generality of the phosphitemediated cyclodehydration (Table 3 ). Towards this end, a range of amino alcohols and diols $\mathbf{1 2} \mathbf{a}, \mathbf{b}$ and $\mathbf{1 2 d}-\mathbf{h}$ were converted in usually very good yields ( $>80 \%$ ) to pyrrolidines, piperidines and furans 13a,b and 13d-h. The established cyclodehydration procedure only had to be slightly modified regarding the work up: As most of the products $13 \mathbf{a}, \mathbf{b}$ and $\mathbf{1 3 d}-\mathbf{h}$ are volatile, the crude reaction mixture was concentrated under reduced pressure (50 mbar) after quenching with the methanolic $\mathrm{KOH}$ solution and kept at this pressure at the rotatory evaporator for ca. $0.5 \mathrm{~h}$. Then the residue was portioned between water and $n$-pentane (high volatility and low solubility of $\left.\mathrm{OP}(\mathrm{OEt})_{3} !\right)$ and the organic phase was washed with five portions of water to remove the remaining phosphate (after saponification $\mathbf{1 3}$ 
Table 3: Cyclodehydration of amino alcohols and diols $12 a-h$ to heterocycles $13 a-h$.

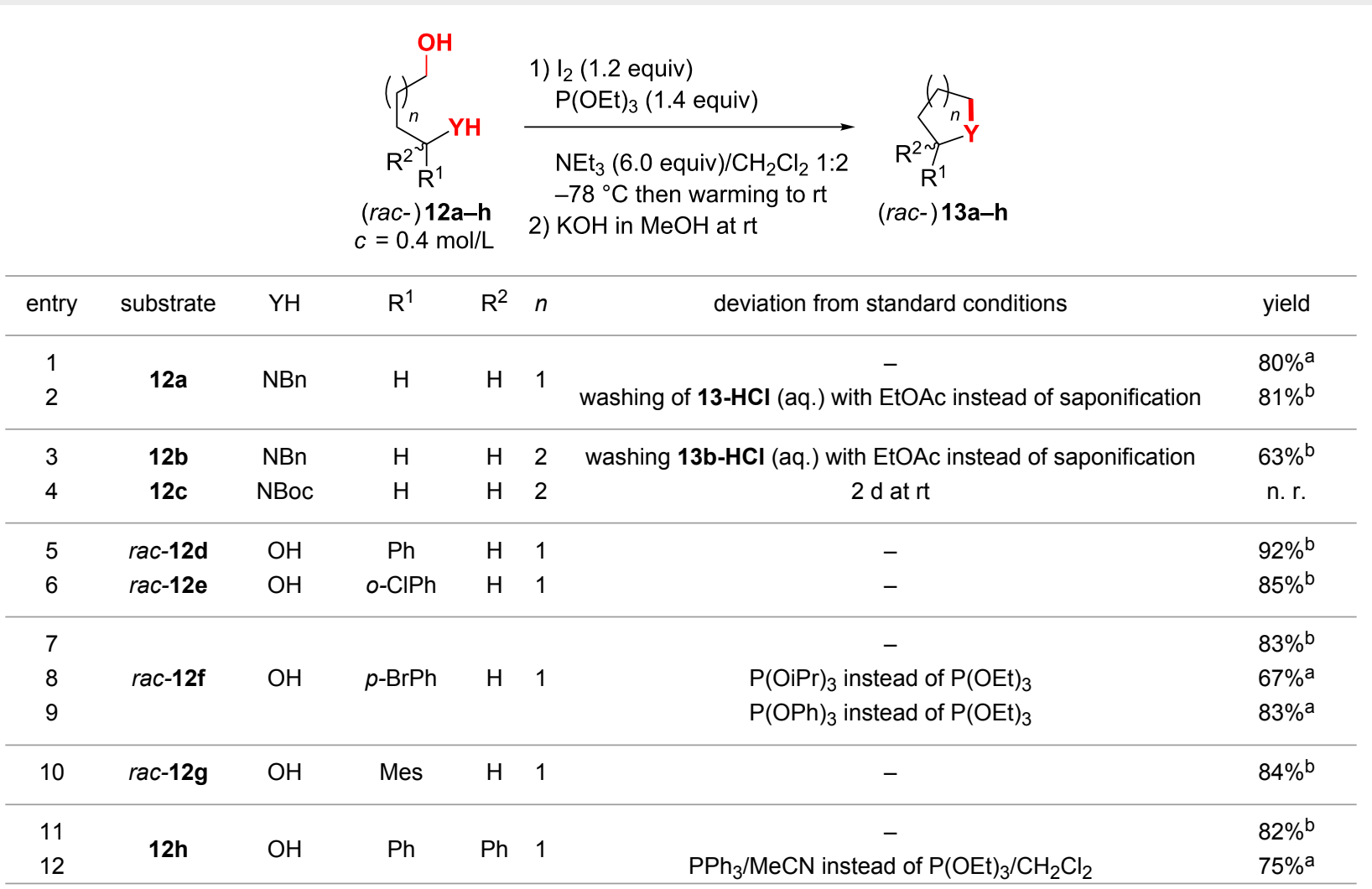

aYield determined with naphthalene as NMR-standard. 'b Isolated yields, purity $>90 \%$ according to crude ${ }^{1} \mathrm{H}$ NMR.

contained $20-30 \mathrm{~mol} \%$ of the phosphate). Finally, the heterocycles 13 were isolated without a trace of the phosphoric acid ester ("traceless cyclodehydration") in $>90 \%$ purity according to ${ }^{1} \mathrm{H}$ NMR.

We first investigated the amino alcohols 12a-c: Pyrrolidine 13a was formed in $80 \%$ yield after hydrolysis of the phosphate and in $81 \%$ yield after extraction of triethylphosphate with EtOAc $(\times 5)$ while keeping the product 13a as the hydrochloride salt in the aqueous phase (Table 3, entries 1 and 2). Surprisingly, with the higher homologue $\mathbf{1 2 b}$ the piperidine $\mathbf{1 3 b}$ was obtained in only $63 \%$ yield (entry 3 ). The lower yield compared to the hydroxypiperidines 11a,b and 11d ( $\geq 74 \%$, see Table 2$)$ might be explained by the preference of a conformation of the phosphonium intermediate III of 11a,b and 11d (Scheme 5), which is favourable for the cyclisation. This arrangement might be stabilized through a hydrogen bridge between the $\mathrm{NH}$ proton and the $\mathrm{O}$ atom of the secondary $\mathrm{OH}$ group and a (weak) Thorpe-Ingold effect by the substituent R. The much less nucleophilic Boccarbamate 12c was not converted to the desired piperidine 13c (entry 4). Here only starting material was re-isolated (probably originating from hydrolysis of the corresponding phosphate of alcohol 12c).
The $\alpha$-aryl furans $\mathbf{1 3 d}-\mathbf{f}$ were formed in excellent yields (83-92\%, Table 3, entries 5-7). Interestingly, the cyclodehydration of rac-12f was also mediated by $\mathrm{P}(\mathrm{OiPr})_{3}$ and $\mathrm{P}(\mathrm{OPh})_{3}$ in $67 \%$ and $83 \%$ yield, respectively (entries $8-9$ ). Whereas $\mathrm{OP}(\mathrm{OiPr})_{3}$ was hydrolyzed in the work up, $\mathrm{OP}(\mathrm{OPh})_{3}$ was not saponified and therefore still remained in the isolated product 13f. However, considering the atom economy these phosphites do not represent an alternative to $\mathrm{P}(\mathrm{OEt})_{3}$. Even the diols rac$\mathbf{1 2 g}$ and $12 \mathrm{~h}$ with a sterically demanding mesityl and two phenyl substituents, respectively, gave cleanly the furans rac-13g and $\mathbf{1 3 h}$ in good yields (Table 3, entries 10 and 11). Also in terms of isolated yield the phosphite-mediated cyclodehydration of substrate $\mathbf{1 2 h}$ was superior $(82 \%$, Table 3 , entry 11$)$ to the phosphine driven conditions ( $75 \%$, entry 12$)$.

\section{Synthesis of a trans-piperidinol B}

We initially investigated the diastereoselectivity of the reduction of the secondary benzylamino ketone 14a, which was synthesized from hydroxyketone 7a through Cbz-cleavage and basic work up (Scheme 6 and Table 4). According to ${ }^{1} \mathrm{H}$ NMR the hemiacetal of 14a (ca. 1:1 ratio of its epimers) forms an equilibrium with its ketone tautomer in a 1.8:1 ratio. In contrast to hydroxyketones $\mathbf{7 a - d}$ the furan tautomer of $\mathbf{1 4 a}$ is thermody- 


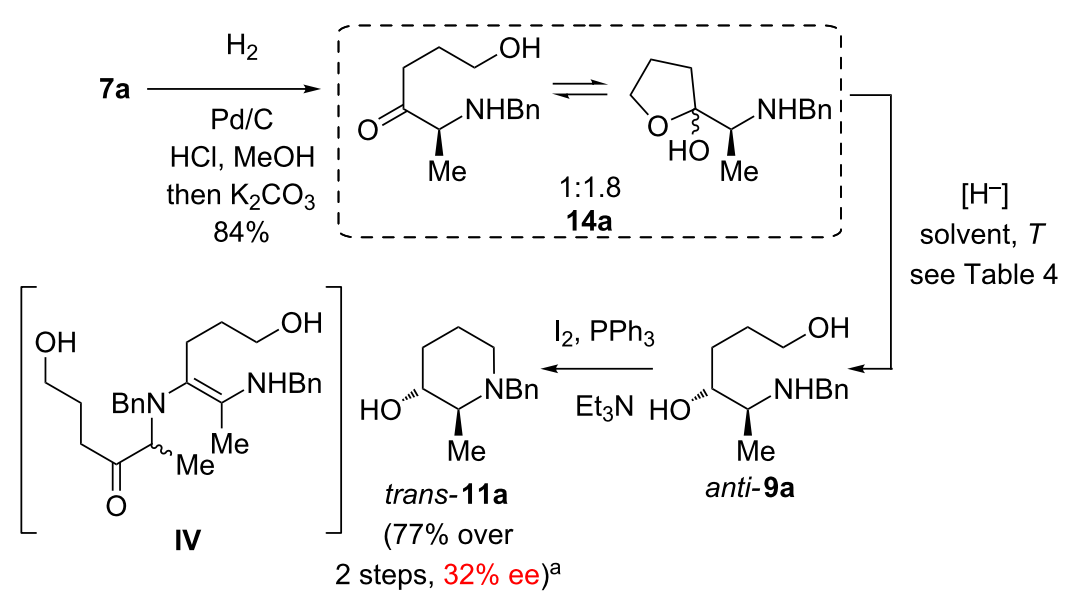

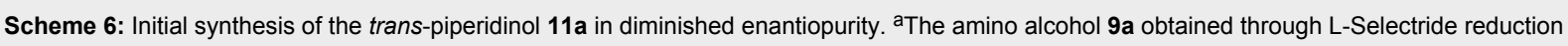
according to entry 6 in Table $4(\mathrm{dr}=25: 1)$ was subjected to cyclodehydration.

namically more stable than the keto form. This might be rationalized by a lower steric strain in the heterocyclic form due to the smaller NHBn side chain (compared to NBnCbz in $\mathbf{7 a - d}$ ).

Disappointingly, in the reduction with $\mathrm{NaBH}_{4}$ no selectivity was observed at all $(\mathrm{dr}=1: 1 \mathrm{anti} / \mathrm{syn}$, Table 4 , entry 1$)$. However, in the presence of one equivalent of $\mathrm{HCl}$ the diol 9a was isolated in a moderate dr of 2.6:1 (entry 2), which demonstrated the formation of a Cram chelate transition state stabilized through a hydrogen bond of the hydrochloride of 14a. Under Luche conditions $\left(\mathrm{NaBH}_{4}, \mathrm{CeCl}_{3}\right)$ [86] a similar result was attained $(\mathrm{dr}=2.9: 1$, Table 4 , entry 3$)$.

DIBALH delivered amino alcohol 9a (various solvents tested) only in poor selectivities (dr up 2.6:1, Table 4, entry 4), which

\begin{tabular}{|c|c|c|c|c|}
\hline entry & {$[\mathrm{H}-]$} & solvent & $T\left[{ }^{\circ} \mathrm{C}\right]$ & $\mathrm{dr}$ (antilsyn) \\
\hline 1 & $\mathrm{NaBH}_{4}$ & $\mathrm{MeOH}$ & 0 & $1: 1^{a}$ \\
\hline 2 & $\mathrm{NaBH}_{4}, \mathrm{HCl}$ & $\mathrm{MeOH}$ & 0 & $2.6: 1^{a}$ \\
\hline 3 & $\mathrm{NaBH}_{4}, \mathrm{CeCl}_{3}$ & $\mathrm{MeOH}$ & -78 & $2.9: 1^{\mathrm{a}}$ \\
\hline 4 & DIBALH & divers $^{\mathrm{b}}$ & -78 & $1.4-2.6: 1^{c}$ \\
\hline 5 & L-Selectride & THF & -78 & $6: 1^{d}$ \\
\hline 6 & L-Selectride & $\mathrm{CH}_{2} \mathrm{Cl}_{2} / \mathrm{THF}^{\mathrm{d}}$ & -78 & $25: 1^{e}$ \\
\hline 7 & $\mathrm{~N}$-Selectride & THF & -78 & $>50: 1^{e}$ \\
\hline
\end{tabular}

${ }^{a}$ The amino alcohol 9 a was isolated in $87 \%$ (entry 1), $85 \%$ (entry 2), $93 \%$ (entry 3 ) yield and $>90 \%$ purity according to ${ }^{1} \mathrm{H} \mathrm{NMR} .{ }^{\mathrm{b}} \mathrm{CH}_{2} \mathrm{Cl}_{2}$, $n$-Hex/THF or $n$-Hex $/ \mathrm{CH}_{2} \mathrm{Cl}_{2}$. ${ }^{\mathrm{c}} 40-60 \%$ conversion were achieved, starting material was not separated. ${ }^{\mathrm{d} A}$ solution of the starting material 14a in $\mathrm{CH}_{2} \mathrm{Cl}_{2}$ was treated with a commercial solution of $L-S e l e c t r i d e$ in THF. ${ }^{\mathrm{e}} 60-80 \%$ conversion were achieved, starting material was not separated. is in harsh contrast to previously reported reductions of related para-methoxybenzylamino and benzylamino ketones with DIBALH giving rise of the best diastereoselectivities [59,60]). Albeit up to four equivalents of DIBALH were utilized, only $40-60 \%$ conversion of $\mathbf{1 4 a}$ was reached. Here the complexation by $-\mathrm{AliBu}_{2}$ after the initial deprotonation of the $\mathrm{OH}$ and $\mathrm{NH}$ function of 14a might shield the carbonyl group and encumber reduction.

However, L-Selectride reduction resulted in better stereoselectivities with $\mathrm{dr}=6: 1$ anti/syn (Table 4 , entry 5 ). If the starting material 14a was dissolved in the less polar $\mathrm{CH}_{2} \mathrm{Cl}_{2}$ (rather than THF), the dr further increased to $>19: 1$ (entry 6). Moreover, $\mathrm{N}$-Selectride provided the product $9 \mathbf{a}$ almost as a pure diastereomer (entry 7, solvent THF), only a very small trace of the syndiastereomer was visible in the ${ }^{1} \mathrm{H}$ NMR (400 MHz). Nevertheless, even with 4 equivalents of Selectride conversions of only up to $80 \%$ were observed. Unfortunately, subsequent Appel reaction of the diol anti-9a $(\mathrm{dr}=25: 1)$, synthesized through L-Selectride reduction in $\mathrm{THF} / \mathrm{CH}_{2} \mathrm{Cl}_{2}$ (Table 4, entry 6), gave piperidinol 11a in a significantly diminished ee of $32 \%$ (determined via HPLC on a chiral stationary phase and comparison with a racemic sample). This racemisation might be rationalized by an intermolecular enamine formation of the secondary amino ketone $\mathbf{1 4 b}$ as depicted in the intermediate IV, Scheme 6.

At this point we realized that a hydrochloride of the secondary amino ketone 14a or a derivative should be unable to racemise through autocatalytic enamine formation (due to the protonation of the amino function). However, the hydrochloride of amine 14a was poorly soluble in organic solvents, so that its isolation proved to be difficult. Straightforward, mesylation of hydroxyketone $7 \mathbf{a}$ and subsequent $\mathrm{Cbz}$-cleavage $\left(\mathrm{H}_{2}, \mathrm{Pd} / \mathrm{C}\right)$ in 


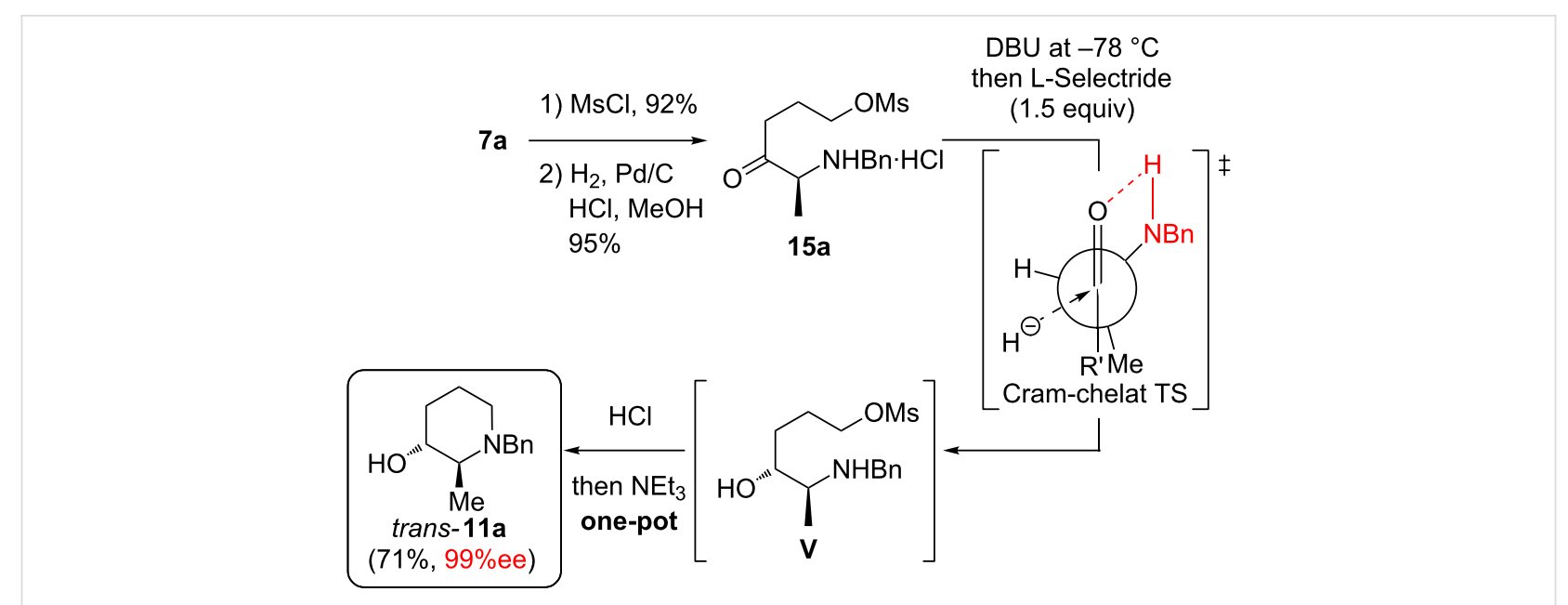

Scheme 7: Synthesis of trans-piperidinol 11a in excellent ee.

the presence of $\mathrm{HCl}$ delivered the hydrochloride salt 15a, which was easily isolated through filtration and solvent evaporation (Scheme 7). To our delight, subsequent liberation of the free amine through DBU at low temperature, immediate L-Selectride reduction (giving intermediate $\mathbf{V}$ ), $\mathrm{HCl}$ quenching and $\mathrm{Et}_{3} \mathrm{~N}$-induced cyclisation afforded the piperidine trans-11a in an excellent ee $(\geq 99 \%)$ and as a single diastereomer according to crude ${ }^{1} \mathrm{H}$ NMR. Although the reduction is performed in the presence of a secondary amino function bearing an $\mathrm{N}-\mathrm{H}$-proton and one equivalent of DBU- $\mathrm{H}^{+}$, only 1.5 equivalents of L-Selectride were required for a quantitative conversion. Thus we assume the Cram chelate transition state is formed through an amine $\mathrm{N}-\mathrm{H}$ proton rather than an amide $\mathrm{N}-\mathrm{Li}$ lithium cation as shown in Scheme 7 (which would result from deprotonation of the amino group by L-Selectride and would thus consume at least 2 equivalents of the reducing agent).

\section{Synthesis of L-733,060}

In order to probe the practicability of our sequence we synthesized L-733,060 as shown in Scheme 8. After cleavage of the Bn-group under 1 atm of hydrogen and subsequent Boc-protec- tion in one pot, the diastereomers cis- and trans-16c were easily separated by flash chromatography. Thereby, we found it advantageous to perform the hydrogenolysis in the presence of $\mathrm{HCl}$ to protonate the released amine and then induce Boc protection after neutralisation of the acid by $\mathrm{Et}_{3} \mathrm{~N}$ rather than to run the hydrogenolysis in the presence of $\mathrm{Boc}_{2} \mathrm{O}$. As already observed in the reduction/Cbz-cleavage $\mathbf{7} \rightarrow \mathbf{9}$ (Scheme 4 ) the quality of the $\mathrm{Pd} / \mathrm{C}$ batch had a high influence on the hydrogenolysis: No Bn cleavage was observed with $\mathrm{Pd} / \mathrm{C}$ charges of a low activity, more catalytically active batches and freshly prepared $\mathrm{Pd} / \mathrm{C}$ [77] led to quantitative conversion within 1-2 d (1 atm $\left.\mathrm{H}_{2}\right)$. The resulting alcohol cis-16c was subjected to Williamson etherification and subsequently the Boc-group was cleaved under acidic conditions ( $\mathrm{HCl}$ in dioxane). We decided to isolate L-733,060 as its hydrochloride salt, because it is a non-hygroscopic solid (rather than an oil) and can be easily extracted with organic solvents (e.g. EtOAc) from an aqueous phase. With 8 steps, our sequence represents one of the shortest syntheses reported to date [38-40]. Additionally, with the carbamate cis-16c (synthesized in 6 rather than 8 steps) we also achieved a formal total synthesis of CP-99,994 [87].

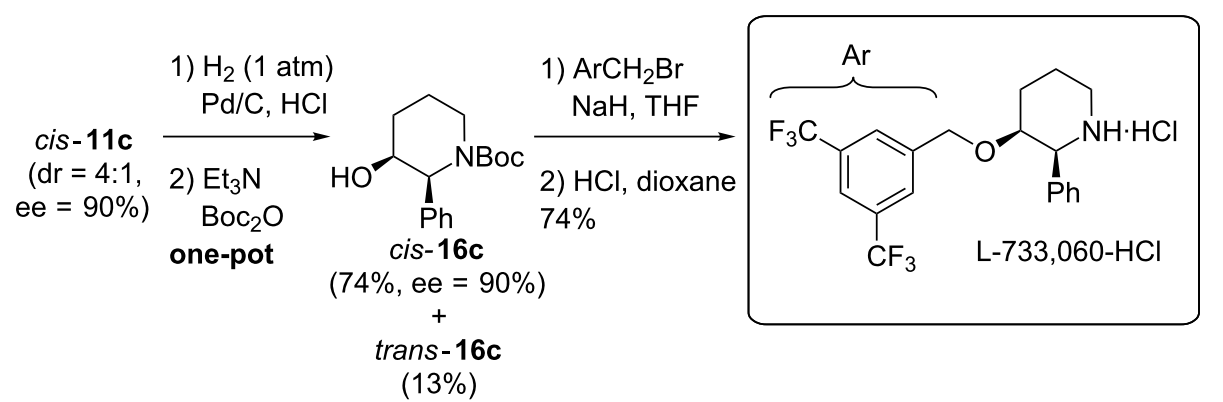


Although the phenylalanine and phenylglycine-derived piperidinols 11b and 11c bear "unfunctionalized" side chains, phenyl groups represent masked carboxylic acid functions. For instance, the enantiomers of piperidine cis-11c and its $N$-deprotected derivative were converted to $(2 S, 3 R)$-3-hydroxypipecolic acid through protecting group manipulation and oxidative cleavage of the phenyl group with $\mathrm{RuCl}_{3}$ and $\mathrm{NaIO}_{4}[38,40]$.

\section{Conclusion}

Herein we presented a highly stereodivergent (dr up to 19:1), scalable and practical (up to $14 \mathrm{~g}$ of cis-11a without any purification of intermediates) synthesis of cis- and trans-configured 3-piperidinols 11, which represent a key structural motive in various natural products and other bioactive target compounds. Moreover, a high step-economy (5-6 steps) was guaranteed by several novel one-pot procedures $(\mathbf{1} \rightarrow \mathbf{2}, \mathbf{7} \rightarrow$ syn-9, $\mathbf{1 5 a} \rightarrow$ trans11a) and surrendering any protection of $\mathrm{OH}$ functions. To probe the efficiency of this sequence piperidinol 11c was converted to the NK-1 inhibitor L-733,060 in three further steps. Additionally, a unique cyclodehydration procedure replacing $\mathrm{PPh}_{3}$ through $\mathrm{P}(\mathrm{OEt})_{3}$ to improve atom economy (166 compared to $262 \mathrm{~g} / \mathrm{mol}$ ) and to allow separation of the oxidized side product $\left(\mathrm{OP}(\mathrm{OEt})_{3}\right)$ by saponification (no similar literature precedents known) was implemented. Ongoing research is focusing on the transformation of the methionine-derived piperidinol 11d to other pharmacologically relevant targets on a gram scale.

\section{Supporting Information}

\section{Supporting Information File 1 \\ Experimental and characterisation data. [http://www.beilstein-journals.org/bjoc/content/ supplementary/1860-5397-10-35-S1.pdf]}

\section{Acknowledgements}

We want to thank the German Academic Exchange Service (DAAD) for a generous scholarship for P. H., and Prof. Dr. H.-G. Schmalz for the very kind opportunity to perform a part of the project at the University of Cologne. Additionally, we want to thank Christopher Lood (Aalto University) for recording analytical data.

\section{References}

1. Karjalainen, O. K.; Koskinen, A. M. P. Org. Biomol. Chem. 2012, 10, 4311-4326. doi:10.1039/c2ob25357g

2. Wijdeven, M. A.; Willemsen, J.; Rutjes, F. P. J. T. Eur. J. Org. Chem. 2010, 2831-2844. doi:10.1002/ejoc.200901494

3. Huang, P.-Q. Synlett 2006, 1133-1149. doi:10.1055/s-2006-941565

4. Nemr, A. L. Tetrahedron 2000, 56, 8579-8629. doi:10.1016/S0040-4020(00)00790-0
5. Bergmeier, S. C. Tetrahedron 2000, 56, 2561-2576 doi:10.1016/S0040-4020(00)00149-6

6. Horne, G.; Wilson, F. X.; Tinsley, J.; Williams, D. H.; Storer, R. Drug Discovery Today 2011, 16, 107-118. doi:10.1016/j.drudis.2010.08.017

7. Winchester, B. G. Tetrahedron: Asymmetry 2009, 20, 645-651. doi:10.1016/j.tetasy.2009.02.048

8. Pruett, S. T.; Bushnev, A.; Hagedorn, K.; Adiga, M.; Haynes, C. A.; Sullards, M. C.; Liotta, D. C.; Merrill, A. H., Jr. J. Lipid Res. 2008, 49, 1621-1639. doi:10.1194/jlr.R800012-JLR200

9. Brunner, M.; Koskinen, A. M. P. Curr. Org. Chem. 2004, 8, 1629-1645. doi:10.2174/1385272043369638

10. Zappia, G.; Cancelliere, G.; Gacs-Baitz, E.; Delle Monache, G.; Misiti, D.; Nevolam, L.; Botta, B. Curr. Org. Synth. 2007, 4, 238-307. doi:10.2174/157017907781369306

11. Ager, D. J.; Prakash, I.; Schaad, D. R. Chem. Rev. 1996, 96, 835-875. doi:10.1021/cr9500038

12. Singh, P. K.; Singh, V. K. Pure Appl. Chem. 2012, 84, 1651-1657. doi:10.1351/PAC-CON-11-10-16

13. Nishiyama, H.; Ito, J.-i. Chem. Commun. 2010, 46, 203-212. doi:10.1039/b918923h

14. Desimoni, G.; Faita, G.; Jørgensen, K. A. Chem. Rev. 2006, 106, 3561-3651. doi:10.1021/cr0505324

15. Baker, R.; Harrison, T.; Swain, C. J.; Williams, B. J. J. Eur. Patent 0528495A1, 1993.

16. Harrison, T.; Williams, B. J.; Swain, C. J.; Ball, R. G. Bioorg. Med. Chem. Lett. 1994, 4, 2545-2550. doi:10.1016/S0960-894X(01)80280-8

17. Desai, M. C.; Lefkowitz, S. L.; Thadeio, P. F.; Longo, K. P.; Snider, R. M. J. Med. Chem. 1992, 35, 4911-4913. doi:10.1021/jm00104a018

18. Rosen, T.; Seeger, T. F.; McLean, S.; Desai, M. C.; Guarino, K. J.; Bryce, D.; Pratt, K.; Heym, J. J. Med. Chem. 1993, 36, 3197-3201. doi:10.1021/jm00073a022

19. Data, P.; Srivastava, S.; Coutinho, E.; Govil, G. Curr. Top. Med. Chem. 2004, 4, 75-103. doi:10.2174/1568026043451636

20. Koepfli, J. B.; Mead, J. F.; Brockman, J. A., Jr. J. Am. Chem. Soc. 1947, 69, 1837. doi:10.1021/ja01199a513

21. Koepfli, J. B.; Mead, J. F.; Brockman, J. A., Jr. J. Am. Chem. Soc. 1949, 71, 1048-1054. doi:10.1021/ja01171a080

22. Linder, M. R.; Heckeroth, A. R.; Najdrowski, M.; Daugschies, A.; Schollmeyer, D.; Miculka, C. Bioorg. Med. Chem. Lett. 2007, 17, 4140-4143. doi:10.1016/j.bmcl.2007.05.053

23. Grauer, A.; König, B. Eur. J. Org. Chem. 2009, 5099-5111. doi:10.1002/ejoc.200900599

24. Hanessian, S.; McNaughton-Smith, G.; Lombart, H.-G.; Lubell, W. D. Tetrahedron 1997, 53, 12789-12854. doi:10.1016/S0040-4020(97)00476-6

25. Maillard, M. C.; Brookfield, F. A.; Courtney, S. M.; Eustache, F. M.; Gemkow, M. J.; Handel, R. K.; Johnson, L. C.; Johnson, P. D.; Kerry, M. A.; Krieger, F.; Meniconi, M.; Muñoz-Sanjuán, I.; Palfrey, J. J.; Park, H.; Schaertl, S.; Taylor, M. G.; Weddell, D.; Dominguez, C. Bioorg. Med. Chem. 2011, 19, 5833-5851. doi:10.1016/j.bmc.2011.08.020

26. Quibell, M.; Benn, A.; Flinn, N.; Monk, T.; Ramjee, M.; Wang, Y.; Watts, J. Bioorg. Med. Chem. 2004, 12, 5689-5710. doi:10.1016/j.bmc.2004.07.054

27. Guengerich, F. P.; DiMari, S. J.; Broquist, H. P. J. Am. Chem. Soc. 1973, 95, 2055-2056. doi:10.1021/ja00787a080

28. Elbein, A. D. FASEB J. 1991, 5, 3055-3063. 
29. Teitelbaum, S. L.; Deselm, C. J. U.S. Pat. Appl. Publ. US 20110311519 A1, 2011.

30. Keller, T.; Mazitschek, R.; Whitman, M.; Lee, J. US Patent 2011/0263532 A1, 2011.

31. Keller, T.; Mazitschek, R.; Whitman, M. PCT Int. Appl. WO 2010019210 A2, 2010.

32. Cochi, A.; Pardo, D. G.; Cossy, J. Heterocycles 2012, 86, 89-116. doi:10.3987/REV-12-SR(N)2

Review on the synthesis of L-733,060 and L-733,061.

33. Cochi, A.; Pardo, D. G.; Cossy, J. Eur. J. Org. Chem. 2013, 809-829. doi:10.1002/ejoc.201201415 Reviews on the synthesis of (3-hydroxy)pipecolic acid derivatives.

34. Cant, A. A.; Sutherland, A. Synthesis 2012, 44, 1935-1950. doi:10.1055/s-0031-1289767

Reviews on the synthesis of (3-hydroxy)pipecolic acid derivatives.

35. Kadouri-Puchot, C.; Comesse, S. Amino Acids 2005, 29, 101-130. doi:10.1007/s00726-005-0193-x Reviews on the synthesis of (3-hydroxy)pipecolic acid derivatives.

36. Lemire, A.; Grenon, M.; Pourashraf, M.; Charette, A. B. Org. Lett. 2004, 6, 3517-3520. doi:10.1021/ol048624n

37. Cossy, J.; Dumas, C.; Pardo, D. G. Eur. J. Org. Chem. 1999, 1693-1699. doi:10.1002/(SICI)1099-0690(199907)1999:7<1693::AID-EJOC1693>3 .0.CO;2-J

38. Cochi, A.; Burger, B.; Navarro, C.; Pardo, D. G.; Cossy, J.; Zhao, Y.; Cohen, T. Synlett 2009, 2157-2161. doi:10.1055/s-0029-1217568

39. Bilke, J. L.; Moore, S. P.; O'Brien, P.; Gilday, J. Org. Lett. 2009, 11, 1935-1938. doi:10.1021/ol900366m

40. Pansare, S. A.; Paul, E. K. Org. Biomol. Chem. 2012, 10, 2119-2125. doi:10.1039/c2ob06644k

41. Shioiri, T.; Izawa, K.; Konoike, T.; Karpf, M. Pharmaceutical Process Chemistry; Wiley-VCH: Weinheim, Germany, 2010; pp 1-37.

42. Roberge, D. M. Org. Process Res. Dev. 2004, 8, 1049-1053. doi:10.1021/op0400160

43. Constable, D. J. C.; Dunn, P. J.; Hayler, J. D.; Humphrey, G. R.; Leazer, J. L., Jr.; Linderman, R. J.; Lorenz, K.; Manley, J.; Pearlman, B. A.; Wells, A.; Zaks, A.; Zhang, T. Y. Green Chem. 2007, 9, 411-420. doi:10.1039/b703488c

44. Dandapani, S.; Curran, D. P. Chem.-Eur. J. 2004, 10, 3130-3138. doi:10.1002/chem.200400363

45. Dembinski, R. Eur. J. Org. Chem. 2004, 2763-2772. doi:10.1002/ejoc.200400003

46. Véliz, E. A.; Beal, P. A. Tetrahedron Lett. 2006, 47, 3153-3156. doi:10.1016/j.tetlet.2006.02.138

47. Chang, B. C.; Conrad, W. E.; Denney, D. B.; Denney, D. Z.; Edelman, R.; Powell, R. L.; White, D. W. J. Am. Chem. Soc. 1971, 93, 4004-4009. doi:10.1021/ja00745a031

48. Denney, D. B.; Denney, D. Z.; Gigantino, J. J. J. Org. Chem. 1984, 49, 2831-2832. doi:10.1021/jo00189a044

49. Kelly, B. D.; Lambert, T. H. Org. Lett. 2011, 13, 740-743. doi:10.1021/ol102980t

50. Flamme, E. M.; Roush, W. R. Beilstein J. Org. Chem. 2005, 1, No. 7. doi:10.1186/1860-5397-1-7

51. Huy, P. H.; Koskinen, A. M. P. Org. Lett. 2013, 15, 5178-5181. doi:10.1021/ol4026588

52. Cherest, M.; Felkin, H.; Prudent, N. Tetrahedron Lett. 1968, 9, 2199-2204. doi:10.1016/S0040-4039(00)89719-1 Introduction of Felkin-Anh model.
53. Stevens, C. L.; TerBeek, K. J.; Pillai, P. M. J. Org. Chem. 1974, 39, 3943-3946. doi:10.1021/jo00940a035

An early example of diastereodiscriminating reductions of amino ketones.

54. Cram, D. J.; Wilson, D. R. J. Am. Chem. Soc. 1963, 85, 1245-1249. doi:10.1021/ja00892a008 Introduction of Cram chelate model.

55. Rittle, K. E.; Homnick, C. F.; Ponticello, G. S.; Evans, B. E. J. Org. Chem. 1982, 47, 3016-3018. doi:10.1021/jo00136a045

56. Lubell, W. D.; Rapoport, H. J. Am. Chem. Soc. 1987, 109, 236-239. doi:10.1021/ja00235a035

57. Reyes, E.; Ruiz, N.; Vicario, J. L.; Badia, D.; Carrillo, L. Synthesis 2011, 443-450. doi:10.1055/s-0030-1258390

58. Fraser, D. S.; Park, S. B.; Chong, J. M. Can. J. Chem. 2004, 82, 87-101. doi:10.1139/V03-165

59. Chung, S.-K.; Lee, J.-M. Tetrahedron: Asymmetry 1999, 1441-1444. doi:10.1016/S0957-4166(99)00147-0

60. Dondoni, A.; Perrone, A. Synthesis 1993, 1162-1176. doi:10.1055/s-1993-26021

61. Quitt, P.; Hellerbach, J.; Vogler, K. Helv. Chim. Acta 1963, 46, 327-333. doi:10.1002/hlca.19630460133

62. Schotten, C. Ber. Dtsch. Chem. Ges. 1884, 17, 2544-2547. doi:10.1002/cber.188401702178

63. Baumann, E. Ber. Dtsch. Chem. Ges. 1886, 19, 3218-3222. doi:10.1002/cber.188601902348

64. Anderson, G. W.; Zimmerman, J. E.; Callaha, F. M. J. Am. Chem. Soc. 1967, 89, 5012-5017. doi:10.1021/ja00995a032 Report about NMM preventing racemisation during peptide coupling due to its low basicity.

65. Wissmann, H.; Kleiner, H.-J. Angew. Chem., Int. Ed. Engl. 1980, 19, 133-134. doi:10.1002/anie.198001331

66. Wissmann, H. Phosphorus Sulfur Relat. Elem. 1987, 30, 645-648. doi:10.1080/03086648708079147

67. Dunetz, J. R.; Xiang, Y.; Baldwin, A.; Ringling, J. Org. Lett. 2012, 13, 5048-5051. doi:10.1021/ol201875q

A recent study towards the amidation of an racemisation sensitive amino acid derivative.

68. Smith, G. G.; Sivakua, T. J. Org. Chem. 1983, 48, 627-634. doi:10.1021/jo00153a001

69. Cahiez, G.; Alexakis, A.; Normant, J. F. Tetrahedron Lett. 1978, 33, 3013-3014. doi:10.1016/S0040-4039(01)94926-3

70. Hanby, W. E.; Waley, S. G.; Watson, J. J. Chem. Soc. 1950, 3239-3249. doi:10.1039/JR9500003239 Selective monoesterification of glutamic acid.

71. Gmeiner, P.; Feldman, P. F.; Chu-Moyer, M. Y.; Rapoport, H. J. Org. Chem. 1990, 55, 3068-3074. doi:10.1021/jo00297a023 Selective side chain monoesterifications of aspartic acid.

72. Schwarz, H.; Bumpus, F. M.; Page, I. H. J. Am. Chem. Soc. 1957, 79, 5697-5703. doi:10.1021/ja01578a030

73. Hannachi, J.-C.; Vidal, J.; Mulatier, J.-C.; Collet, A. J. Org. Chem. 2004, 69, 2367-2373. doi:10.1021/jo035700b Reductive benzylation of amino acids with $\mathrm{PhCHO}$ and $\mathrm{NaBH}_{4}$ in $\mathrm{MeOH}$.

74. Brown, H. C.; Krishnamurthy, S. J. Am. Chem. Soc. 1972, 94, 7159-7161. doi:10.1021/ja00775a053 Initial discovery of L-Selectride.

75. Brown, H. C.; Krishnamurthy, S. J. Am. Chem. Soc. 1973, 95, 1669-1671. doi:10.1021/ja00786a057 Initial development of Superhydride. 
76. Brown, H. C.; Kim, S. C.; Krishnamurthy, S. J. Org. Chem. 1980, 45, 1-12. doi:10.1021/jo01289a001

Initial development of Superhydride.

77. Felpin, F.-X.; Fouquet, E. Chem.-Eur. J. 2010, 16, 12440-12445. doi:10.1002/chem.201001377

78. Khan, I. A.; Saxena, A. K. Tetrahedron 2012, 68, 1272-1279. doi:10.1016/j.tet.2011.11.047

79. Kobrzycka, E.; Gryko, D.; Jurczak, J. Tetrahedron: Asymmetry 2002, 13, 2133-2139. doi:10.1016/S0957-4166(02)00545-1

80. Griengl, H.; Hayden, W.; Schindler, E.; Wanek, E. Arch. Pharm. 1983, 316, 146-153. doi:10.1002/ardp.19833160211

81. Appel, R.; Kleinstück, R. Chem. Ber. 1974, 107, 5-12. doi:10.1002/cber.19741070102

82. Lange, G. L.; Gottardo, C. Synth. Commun. 1990, 20, 1473-1479. doi:10.1080/00397919008052864 Cyclodehydration with $\mathrm{I}_{2}$ and $\mathrm{PPh}_{3}$

83. Stowell, J. K.; Widlanski, T. S. Tetrahedron Lett. 1995, 36, 1825-1826. doi:10.1016/0040-4039(95)00153-4

84. Oza, V. B.; Corcoran, R. C. J. Org. Chem. 1995, 60, 3680-3684. doi:10.1021/jo00117a018

85. Watanabe, Y.; Inada, E.; Jinno, M.; Ozaki, S. Tetrahedron Lett. 1993, 34, 497-500. doi:10.1016/0040-4039(93)85111-9

86. Gemal, A. L.; Luche, J. L. J. Am. Chem. Soc. 1981, 103, 5454-5459. doi:10.1021/ja00408a029

87. Huang, P.-Q.; Liu, L.-X.; Wei, B.-G.; Ruan, Y.-P. Org. Lett. 2003, 5, 1927-1929. doi:10.1021/ol034505g

\section{License and Terms}

This is an Open Access article under the terms of the Creative Commons Attribution License (http://creativecommons.org/licenses/by/2.0), which permits unrestricted use, distribution, and reproduction in any medium, provided the original work is properly cited.

The license is subject to the Beilstein Journal of Organic Chemistry terms and conditions:

(http://www.beilstein-journals.org/bjoc)

The definitive version of this article is the electronic one which can be found at: $\underline{\text { doi:10.3762/bjoc. } 10.35}$ 